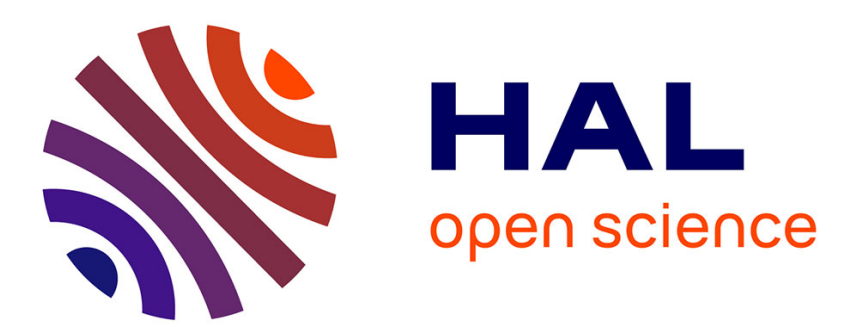

\title{
Electron beam melted Ti-6Al-4V: Microstructure, texture and mechanical behavior of the as-built and heat-treated material
}

Charlotte de Formanoir, Sébastien Michotte, Olivier Rigo, Lionel Germain, Stéphane Godet

\section{To cite this version:}

Charlotte de Formanoir, Sébastien Michotte, Olivier Rigo, Lionel Germain, Stéphane Godet. Electron beam melted Ti-6Al-4V: Microstructure, texture and mechanical behavior of the asbuilt and heat-treated material. Materials Science and Engineering: A, 2016, 652, pp.105-119. 10.1016/j.msea.2015.11.052 . hal-01515327

\section{HAL Id: hal-01515327 \\ https://hal.univ-lorraine.fr/hal-01515327}

Submitted on 20 Feb 2020

HAL is a multi-disciplinary open access archive for the deposit and dissemination of scientific research documents, whether they are published or not. The documents may come from teaching and research institutions in France or abroad, or from public or private research centers.
L'archive ouverte pluridisciplinaire HAL, est destinée au dépôt et à la diffusion de documents scientifiques de niveau recherche, publiés ou non, émanant des établissements d'enseignement et de recherche français ou étrangers, des laboratoires publics ou privés. 


\title{
Electron beam melted Ti-6Al-4V: Microstructure, texture and mechanical behavior of the as-built and heat-treated material
}

\author{
Charlotte de Formanoir ${ }^{\mathrm{a}, *}$, Sébastien Michotte ${ }^{\mathrm{b}}$, Olivier Rigo ${ }^{\mathrm{b}}$, Lionel Germain ${ }^{\mathrm{c}, \mathrm{d}}$, \\ Stéphane Godet ${ }^{a}$ \\ a 4MAT, Université Libre de Bruxelles, 50 Avenue F.D. Roosevelt, 1050 Bruxelles, Belgium \\ birris, T-ADD, 20 rue Auguste Piccard, 6041 Gosselies, Belgium

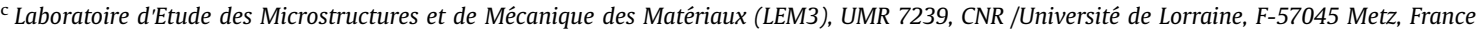 \\ ${ }^{\mathrm{d}}$ Laboratory of Excellence on Design of Alloy Metals for low-mAss Structures ('LabEx DAMAS'), Université de Lorraine, France
}

\section{A R T I C L E I N F O}

\section{Keywords:}

Additive Manufacturing

Electron Beam Melting (EBM)

Ti-6Al-4V

Heat Treatments

Texture

Electron Backscatter Diffraction (EBSD)

\begin{abstract}
A B S T R A C T
Electron Beam Melting (EBM), a powder bed additive layer manufacturing process, was used to produce Ti-6Al-4V specimens, whose microstructure, texture, and tensile properties were fully characterized. The microstructure, analyzed by optical microscopy, SEM/EBSD and X-ray diffraction, consists in fine $\alpha$ lamellae. Numerical reconstruction of the parent $\beta$ phase highlighted the columnar morphology of the prior $\beta$ grains, growing along the build direction upon solidification of the melt pool. The presence of grain boundary $\alpha_{\mathrm{GB}}$ along the boundaries of these prior $\beta$ grains is indicative of the diffusive nature of the $\beta \rightarrow \alpha$ phase transformation. Texture analysis of the reconstructed high temperature $\beta$ phase revealed a strong $<001>$ pole in the build direction. For mechanical characterization, tensile specimens were produced using two different build themes and along several build orientations, revealing that vertically built specimens exhibit a lower yield strength than those built horizontally. The effect of post processing, either mechanical or thermal, was extensively investigated. The influence of surface finish on tensile properties was clearly highlighted. Indeed, mechanical polishing induced an increase in ductility - due to the removal of critical surface defects - as well as a significant increase of the apparent yield strength caused by the removal of a $\sim 150 \mu \mathrm{m}$ rough surface layer that can be considered as mechanically inefficient and not supporting any tensile load. Thermal post-treatments were performed on electron beam melted specimens, revealing that subtransus treatments induce very moderate microstructural changes, whereas supertransus treatments generate a considerably different type of microstructure, due to the fast $\beta$ grain growth occurring above the transus. The heat treatments investigated in this work had a relatively moderate impact on the mechanical properties of the parts.
\end{abstract}

\section{Introduction}

Additive manufacturing (AM) includes various technologies that build objects from a digital model, by laying down successive layers of material. This "bottom-up" and versatile approach contrasts with the more constraining "top-down" approach conventionally adopted in the machining of a part. Electron beam melting (EBM) is a powder bed AM process, similar to selective laser melting (SLM). It consists in building metallic parts by stacking and melting successive layers of powder on top of one another. The parts are built in a vacuum chamber using a highenergy electron gun. A comprehensive description of the process can be found in literature [1-4].

\footnotetext{
* Corresponding author.

E-mail address: cdeforma@ulb.ac.be (C. de Formanoir).
}

AM allows complex geometries to be imagined by designers and successfully implemented by engineers. In the aeronautic industry, it also provides a unique opportunity to considerably reduce the buy-to-fly ratio of flying components, that is, the ratio between the weight of the raw material used to build a part and the actual weight of the part [5]. However, to ensure that the EBM process meets the quality standards required in the production of critical flying components, it is crucial to get a deep and fundamental understanding of the links between process parameters, microstructure development and the resulting mechanical properties. Another key aspect to evaluate is the influence of post treatments, widely used in the aeronautic industry, on the mechanical behavior of the material.

In the EBM chamber, the material undergoes a complex process, characterized by a succession of preheating, melting, rapid cooling (with solidification and phase transformation), and partial re-melting of each layer of powder. Therefore, the EBM technology 


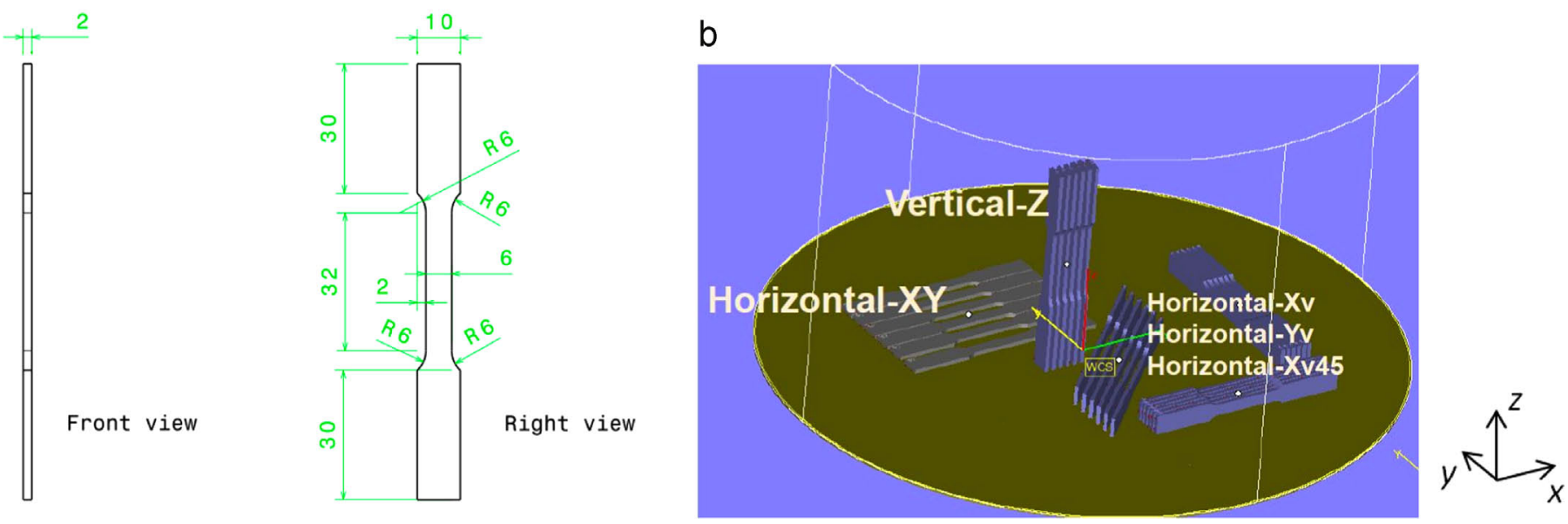

Fig. 1. (a) Geometry of a tensile specimen (dimensions in $\mathrm{mm}$ ) (b) build orientations of the tensile specimens in the EBM chamber, with associated nomenclature.

generates a specific microstructure and texture. Several authors [5-7] have already provided a comprehensive description of the microstructure and texture of as-built electron beam melted Ti$6 \mathrm{Al}-4 \mathrm{~V}$ parts. During the EBM process, the solidification of each layer of molten metal occurs by homoepitaxial growth of the $\beta$ grains, resulting in grains elongated in the direction of the thermal gradient. This columnar microstructure is frequently observed in additively manufactured Ti-6Al-4V [5,6]. During cooling of the metal, when the temperature drops below the transus, phase transformation occurs and fine $\alpha$ lamellae nucleate and grow in the parent $\beta$ grains.

The static mechanical properties of as-built EBM parts have also been extensively studied [6,8-15]. However, a very large range of tensile properties is reported in literature, with yield strength levels ranging from $783 \mathrm{MPa}$ up to $1130 \mathrm{MPa}$ and strains to failure ranging from $2.3 \%$ to $20 \%$ [11,12]. Lack of information concerning the choice of build parameters precludes any quantitative comparison between the different results and any conclusion concerning the impact of these parameters on the properties of the material. These build parameters include geometry and build orientation of the parts, powder chemistry, use of supports, and all the settings of the machine included in the 'build theme'. The build theme involves a large set of process parameters that are supposed to be optimized by the machine manufacturer, i.e. Arcam $A B^{\circledR}$. Differences in the build parameters used in the production of each of the tensile specimens tested might explain the broad range of mechanical properties observed in the literature. The first $o b-$ jective of this work is therefore to improve the fundamental knowledge of the links between process parameters, resulting microstructures and associated mechanical properties. In the present work, Ti-6Al-4V specimens were produced under various conditions, in order to evaluate the influence of manufacturing parameters such as the build theme or the build direction.

The second objective of this work is to evaluate the effect of post-treatments - whether thermal, or mechanical, such as polishing - on the behavior of the material, in an attempt to define optimum post-treatments for parts obtained by EBM. In the industry, post-treatments such as Hot Isostatic Pressing (HIP) are systematically applied for critical parts. Their effect on microstructure evolution and resulting mechanical properties has been seldom studied. Though several heat treatments have been performed on SLM parts [16-19], as far as EBM is concerned, only Hot Isostatic Pressing (HIP) has been investigated $[6,14]$. In the present work, post treatments, either mechanical (polishing) or thermal (subtransus and supertransus heat treatments) were investigated.
Post-EBM polishing allows the impact of the surface condition on the tensile properties to be investigated. As for heat treatments, they were performed in order to evaluate the range of microstructures and resulting mechanical properties that could be obtained from electron beam melted material.

\section{Materials and methods}

The samples were all produced using an Arcam $A B^{\circledR}$ A2 machine. The powder used as starting material in the EBM process was a plasma atomized Ti-6Al-4V ELI powder, provided by Arcam $\mathrm{AB}^{\mathrm{R}}$, with particle size ranging from $0.05 \mu \mathrm{m}$ to $500 \mu \mathrm{m}$ and a volume median diameter of approximately $75 \mu \mathrm{m}$. SEM observation of the powder revealed spherical particles, with a homogeneous morphology, a smooth surface, and few aggregates. It should be highlighted that, with a value of $0.23 \%$, the oxygen content of the powder slightly exceeded the maximum value of $0.2 \%$ required for $\mathrm{Ti}-6 \mathrm{Al}-4 \mathrm{~V}$. The results of the mechanical tests performed in this study should thus be considered as a "worst case scenario", considering the oxygen contamination of the starting material used to build the specimens.

Two types of part geometries were studied: tensile specimens (Fig. 1.a) to evaluate the mechanical properties, and $1 \mathrm{~cm}^{3}$ cubes to analyze the microstructure and texture. For the production of the tensile specimens, two different build themes preset by Arcam $\mathrm{AB}^{\circledR}$ were used, namely the "Ti6Al4V-Melt-70 $\mu \mathrm{m}$ " and "Ti6Al4VMelt-50 $\mu \mathrm{m}$ " themes. Both themes mainly varied by their layer thickness, i.e. the distance over which the build table is moved between two deposition layers. As for the cubes, they were all built using the "Ti6Al4V-Melt-70 $\mu \mathrm{m}$ " theme. For each theme, some key process parameters are reported in Table 1 . The main difference between the two themes is that the "Ti6Al4V-Melt$50 \mu \mathrm{m}$ " theme uses a hatching with halved line offset ${ }^{1}$, a higher speed function ${ }^{2}$, and halved beam width, resulting in a roughly unchanged energy density (Table 1 ). The $50 \mu \mathrm{m}$ theme provides a number of benefits, such as a more precise hatching due to smaller melt pool and smaller hatching line offset, and a faster cooling rate in the high temperature regime. For small builds, the $70 \mu \mathrm{m}$ layer theme is much faster due to the fewer layers and shorter raking

\footnotetext{
${ }^{1}$ The line offset is the offset between two hatch lines.

2 The speed function is an index that controls the beam speed during a build, when melting is in automatic mode. A higher value of the speed function gives a higher speed. For more information, the reader is referred to the complete description of the process parameters delivered by $\operatorname{Arcam~}^{A B} B^{\mathbb{R}}$ [20].
} 
Table 1

Process parameters.

\begin{tabular}{|c|c|c|}
\hline & Ti6Al4V-Melt-70 $\mu \mathrm{m}$ & Ti6Al4V-Melt-50 $\mu \mathrm{m}$ \\
\hline Layer thickness & $70 \mu \mathrm{m}$ & $50 \mu \mathrm{m}$ \\
\hline Power analyze & $\mathrm{ON}$ & $\mathrm{ON}$ \\
\hline Surface temperature & $850^{\circ} \mathrm{C}$ & $850{ }^{\circ} \mathrm{C}$ \\
\hline Melt model wise & OFF & OFF \\
\hline \multicolumn{3}{|l|}{ CONTOURS } \\
\hline Number of contours & $\begin{array}{l}1 \text { outer (offset } 0.3 \mathrm{~mm} \text { ) then } \\
2 \text { inners (offset } 0.25 \mathrm{~mm} \text { ) }\end{array}$ & $\begin{array}{l}1 \text { outer (offset } 0.29 \mathrm{~mm}) \\
\text { then } 1 \text { inner }(0.25 \mathrm{~mm})\end{array}$ \\
\hline $\begin{array}{l}\text { Multispot } \\
\text { HATCH }\end{array}$ & ON & ON \\
\hline Focus offset & $\begin{array}{l}19 \mathrm{~mA} \text { (beam width } \\
\sim 400 \mu \mathrm{m} \text { ) }\end{array}$ & $\begin{array}{l}3 \mathrm{~mA} \text { (beam width } \\
\sim 200 \mu \mathrm{m})\end{array}$ \\
\hline Speed function & 36 & 98 \\
\hline Hatch & "snake $x-y$ "a & “snake $x-y$ " \\
\hline Line offset & $200 \mu \mathrm{m}$ & $100 \mu \mathrm{m}$ \\
\hline
\end{tabular}

The line offset is the offset between two hatch lines.

The speed function is an index that controls the beam speed during a build, when melting is in automatic mode. A higher value of the speed function gives a higher speed. For more information, the reader is referred to the complete description of the process parameters delivered by Arcam $\mathrm{AB}^{\mathrm{R}}{ }^{\mathrm{B}}$ [20].

${ }^{a}$ For each successive layer, the scanning direction is rotated by $90^{\circ}$, i.e. alternates along the $x$ and $y$ axes.

time required. On larger builds with networks and a lot of contours, the $50 \mu \mathrm{m}$ theme tends to be faster [20]. For high and massive builds, the $50 \mu \mathrm{m}$ theme tends to be about $5-10 \%$ slower.

In order to estimate the impact of the build direction on the mechanical behavior, the tensile specimens were built along various orientations, depicted in Fig. 1.b: vertically ("Vertical-Z"), horizontally flat ("Horizontal-XY") or horizontally on the edge ("Horizontal-Xv"). Some of the as-built specimens were mechanically polished (removal of $200-300 \mu \mathrm{m}$ on each side) in order to evaluate the impact of the surface roughness on the mechanical properties.

Various heat treatments were performed on a batch of tensile specimens produced with the "Ti6Al4V-Melt-70 $\mu \mathrm{m}$ " build theme. These specimens were encapsulated in quartz tubes under argon atmosphere in order to avoid oxygen contamination. Two holding temperatures were investigated. The samples were heated either for $1 \mathrm{~h}$ at $950^{\circ} \mathrm{C}$ - a subtransus temperature chosen to simulate the thermal effect of the HIP post treatment, widely used in the aeronautic industry - or for $30 \mathrm{~min}$ at $1040{ }^{\circ} \mathrm{C}$, i.e. above the transus. The influence of the cooling rate was also investigated: the samples were either air cooled (AC) or furnace cooled (FC). Tensile tests were performed on as-built specimens and on heat-treated specimens, at room temperature, up to fracture, with a clip-on extensometer and at a crosshead speed of $1 \mathrm{~mm} / \mathrm{min}$. The resulting fracture surfaces and fracture profiles were characterized by scanning electron microscopy and by optical microscopy, respectively.

As-built electron beam melted cubes as well as heat-treated ones were cut in two halves, with a low speed diamond saw, either perpendicularly to the build direction or along the build direction. They were then mechanically polished. This step was followed by chemical-mechanical polishing using a 90\% colloidal silica suspension and $10 \% \mathrm{H}_{2} \mathrm{O}_{2}$ (30\%) solution. The polished samples were submitted to electron backscatter diffraction (EBSD) analysis, with a step size of $1 \mu \mathrm{m}$. Based on the existence of the Burgers orientation relationship between the body-centered cubic $\beta$ phase and the hexagonal $\alpha$ phase, a numerical reconstruction of the parent $\beta$ grains, from the room temperature $\alpha$ phase EBSD data, was performed. A complete description of the reconstruction procedure can be found in [21]. For optical microscopy, chemical etching with Kroll's reagent ( $2 \% \mathrm{HF}, 4 \% \mathrm{HNO}_{3}$ ) was performed after mechanical and OP-S polishing.
X-ray diffraction as well as high magnification EBSD (x2000, step size of $0.1 \mu \mathrm{m}$ ) were performed on both as-built and heattreated cubes, in order to evaluate and quantify the phase distribution. Analysis of the chemical composition of electron beam melted material was performed: a LECO ONH836 Oxygen/Nitrogen/Hydrogen Elemental Analyzer was used in order to measure oxygen contamination.

\section{Results}

\subsection{As-built specimens: microstructure and texture}

As previously highlighted by several authors ([6,7]) and illustrated in Fig. 2, the microstructure of electron beam melted parts is lamellar, with fine $\alpha$ platelets oriented in various directions. Although some $\alpha$ colonies - i.e. parallel $\alpha$ plates belonging to the same variant of the Burgers relationship - can be observed, most $\alpha$ platelets are individual, which is indicative of a relatively fast cooling rate during the $\beta$ to $\alpha$ phase transformation. Their average width is $1.9 \mu \mathrm{m}$. A continuous $\alpha_{\mathrm{GB}}$ layer can be observed along some grain boundaries of the prior $\beta$ phase.

Numerical reconstructions of the high temperature parent $\beta$ phase are shown in Fig. 3.b and .d. The parent $\beta$ grains are elongated along the build direction, resulting in a highly anisotropic columnar microstructure. Most of these columns are separated from one another by low angle grain boundaries ( $<15^{\circ}$, in white). These "subcolumns" are organized in clusters separated by high angle grain boundaries ( $>15^{\circ}$, in black).

The $<001>$ pole figure corresponding to the reconstructed $\beta$ phase (Fig. 3.f) indicates the presence of a strong pole in the build direction. The two other (001) directions, tend to be aligned with the $x$ and $y$ axes, i.e. the beam raster directions. The resulting texture is cube-like with a fiber component.

The $\alpha$ texture, reported in Fig. 3.e, is weaker than the texture of the high temperature $\beta$ phase. As a result of the Burgers relationship, up to 12 crystallographic $\alpha$ variants can indeed form in each $\beta$ grain during the $\beta \rightarrow \alpha$ transformation, resulting in a substantial decrease in texture intensity.

\subsection{As-built specimens: mechanical properties}

Two different build themes were used for the production of tensile specimens: the "Ti6Al4V-Melt-50 $\mu \mathrm{m}$ " theme and the “Ti6Al4V-Melt-70 $\mu \mathrm{m}$ ” theme (Table 1 ).

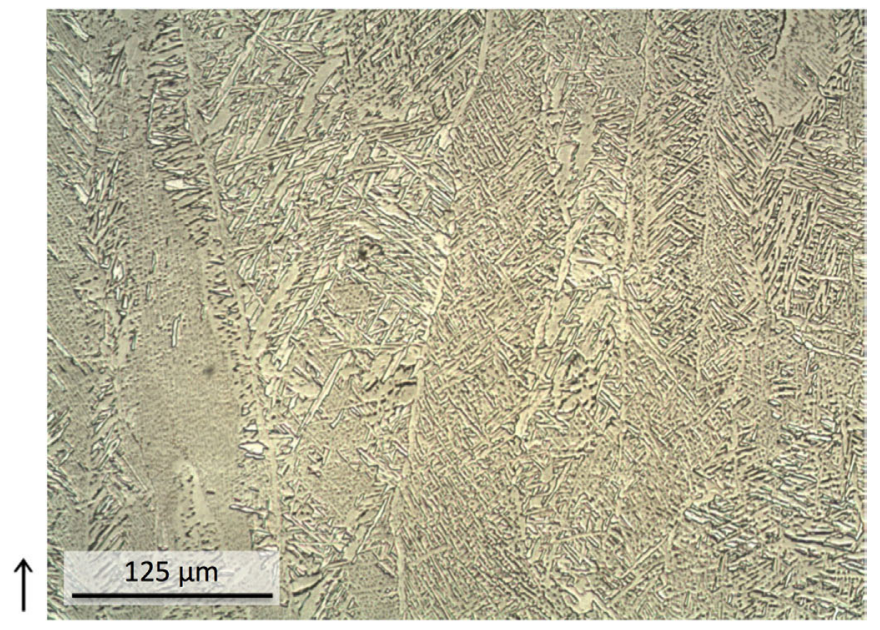

Fig. 2. Optical micrograph of an as-built electron beam melted cube. The arrow indicates the build direction. 


\section{a}

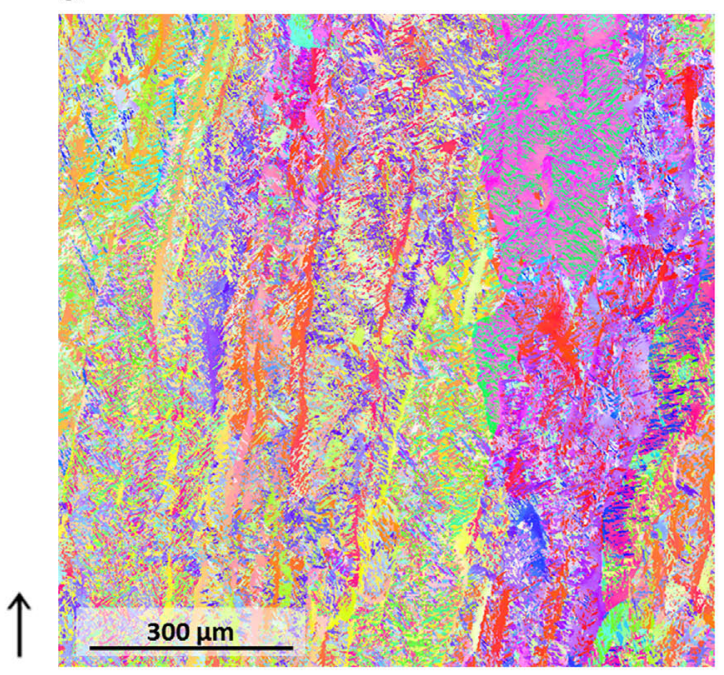

C

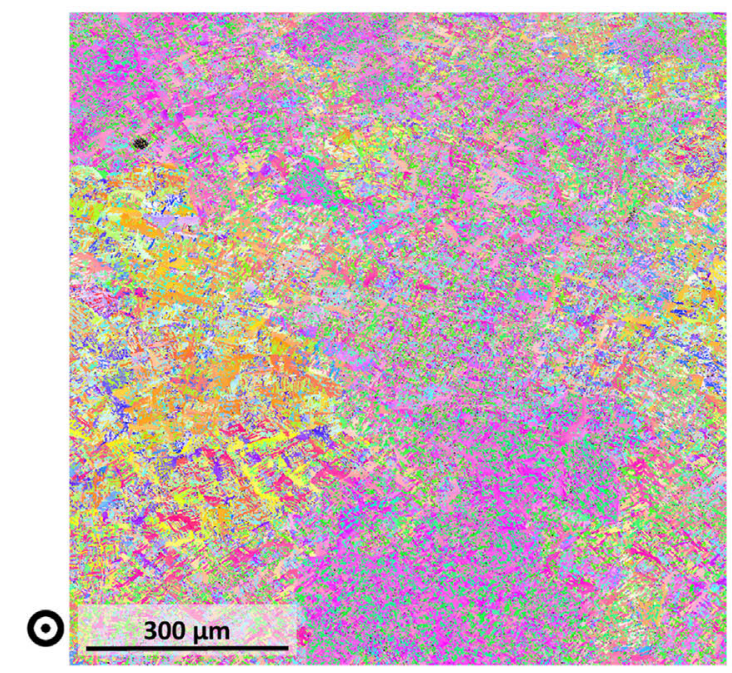

e

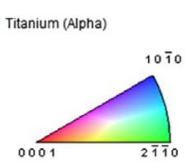

b

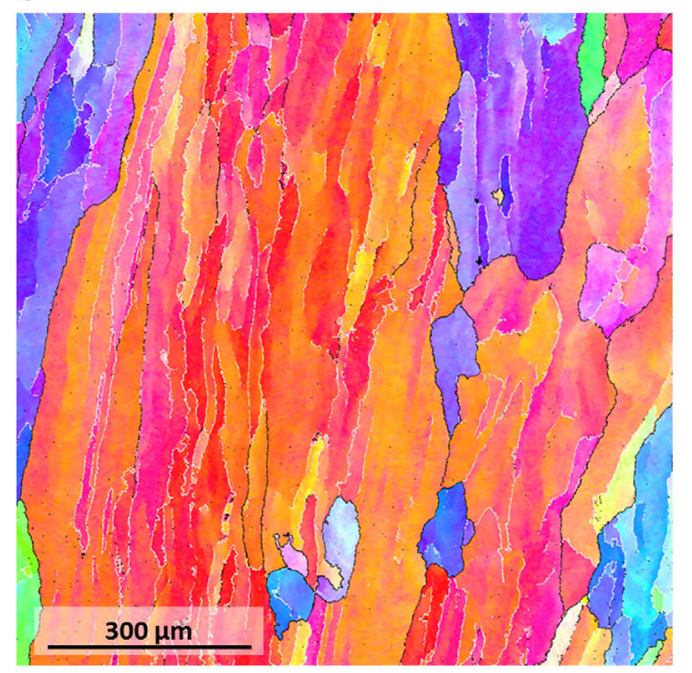

d

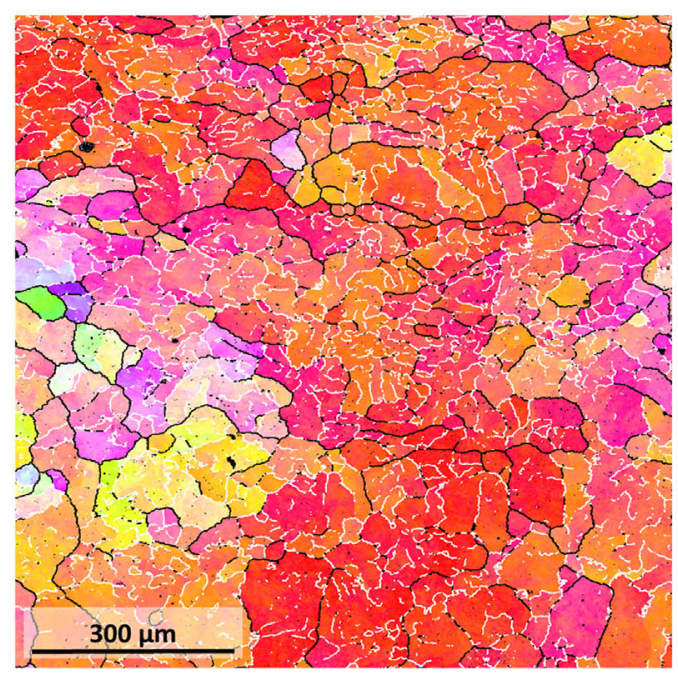

f

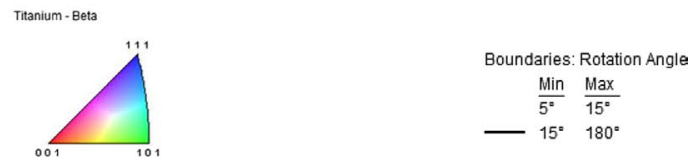

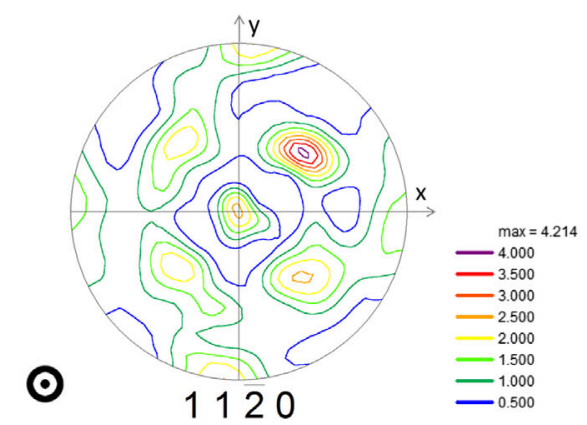

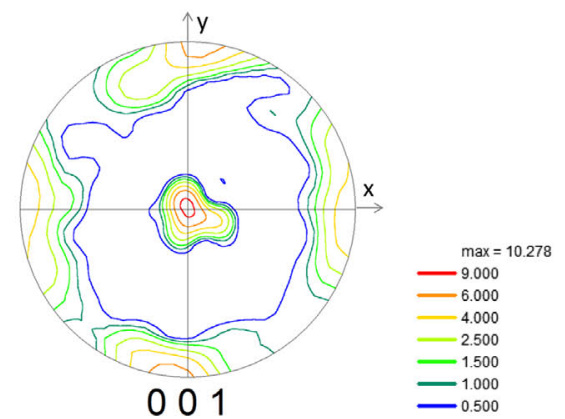

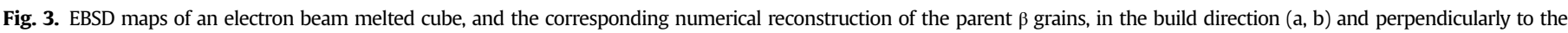

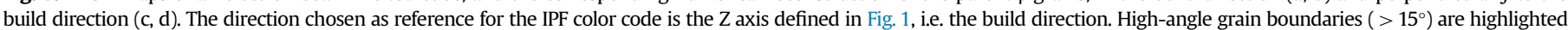

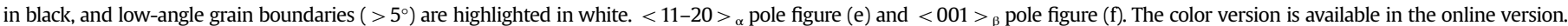

\subsection{1. "Ti6Al4V-Melt-50 $\mu \mathrm{m}$ " build theme}

Eight specimens built in the "Vertical-Z" direction with the "Ti6Al4V-Melt- $50 \mu \mathrm{m}$ " theme were submitted to tensile testing.
Four of them were tested in their as-built condition whereas the four others were polished mechanically before being tested. The resulting engineering stress-strain curves are reported in Fig. 4.a. 
a

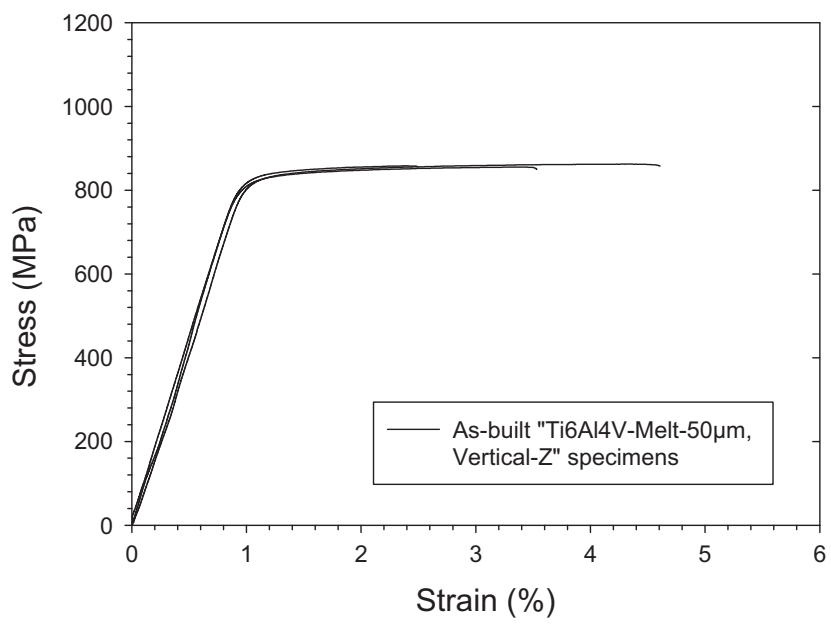

b

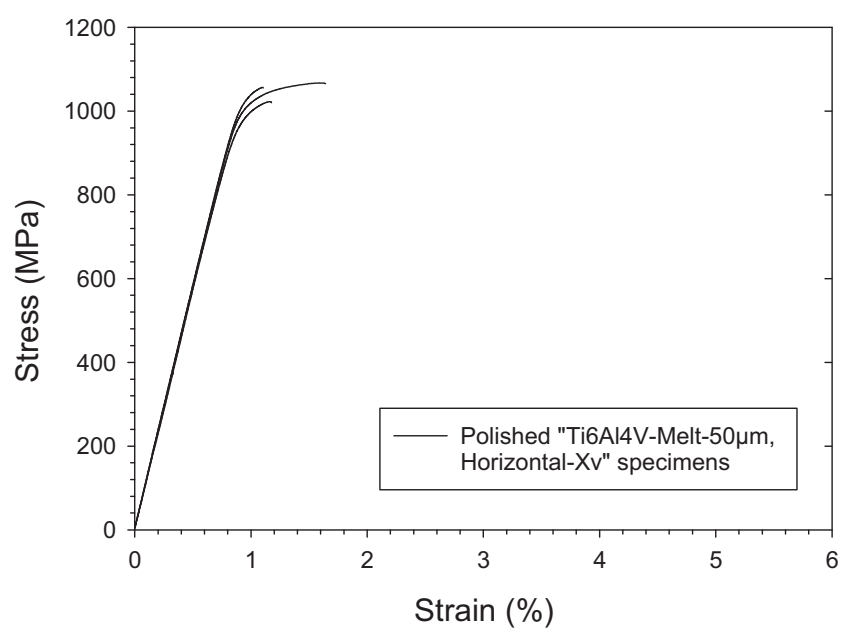

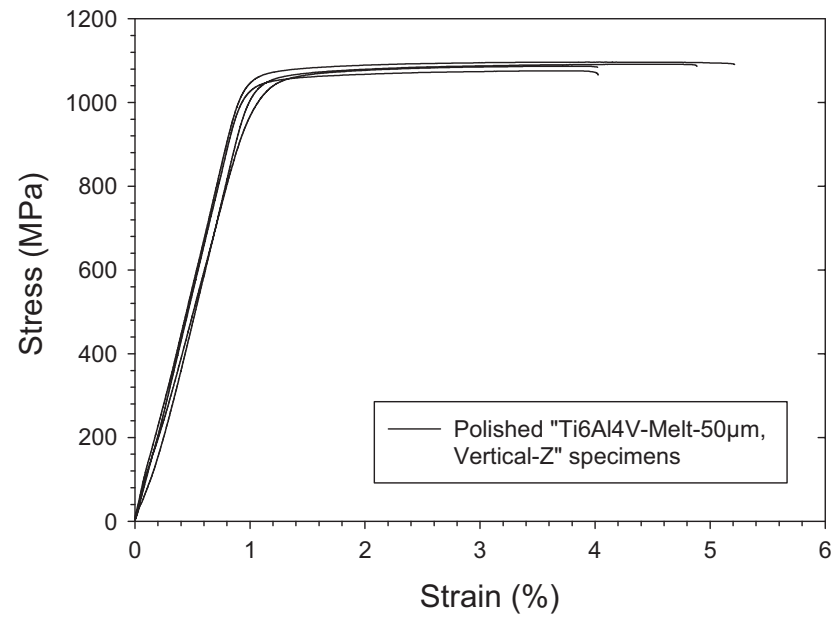

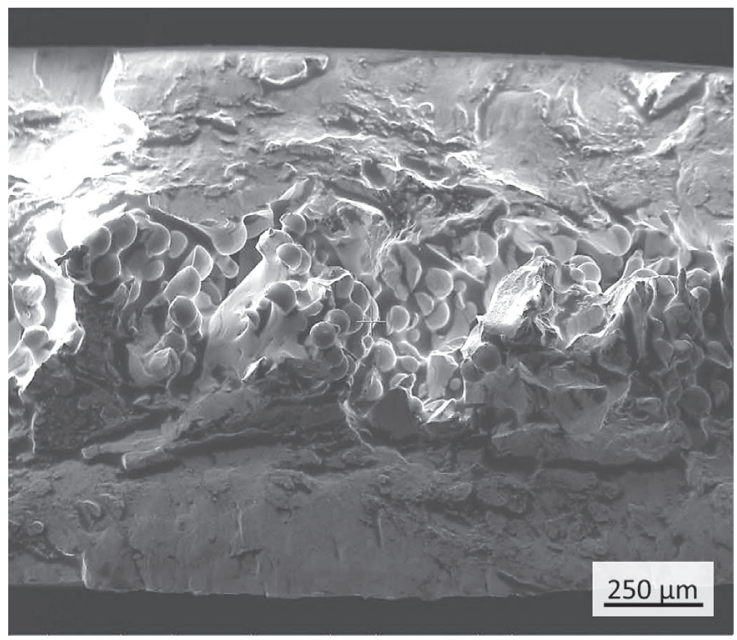

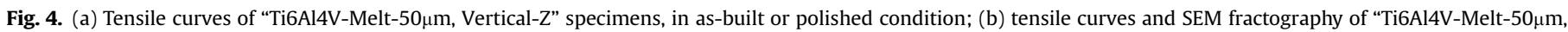
Horizontal-Xv" specimens, in polished conditions.

As-built specimens exhibit a yield stress $\sigma_{\mathrm{y}}$ of $832 \pm 24 \mathrm{MPa}$ and a strain to failure of $3.64 \pm 1.2 \%$. In the case of polished specimens, on the other hand, a yield stress $\sigma_{\mathrm{y}}$ of $1055 \pm 11.5 \mathrm{MPa}$ and a strain to failure of $4.58 \pm 0.78 \%$ were measured.

Four specimens built with the same "Ti6Al4V-Melt-50 $\mu \mathrm{m}$ " theme but in the "Horizontal-Xv" direction were polished and subsequently tested. The resulting engineering tensile curves are shown in Fig. 4.b. A yield strength $\sigma_{\mathrm{y}}$ of $1049 \pm 40 \mathrm{MPa}$ and an extremely low strain to failure of $1.48 \pm 0.57 \%$ were measured.

Fractography performed on these "Horizontal-Xv" specimens revealed the presence of major build defects. Unmelted particles can be observed within large non-spherical voids (Fig. 4.b).

\subsection{2. "Ti6Al4V-Melt-70 4 m" build theme}

In order to further evaluate the influence of the build direction on the mechanical behavior, four specimens were built in each of the three following directions: "Vertical-Z", "Horizontal-Xv" and "Horizontal-XY", with the "Ti6Al4V-Melt-70 $\mu \mathrm{m}$ " build theme. These specimens were polished and submitted to tensile tests, whose results are reported in Fig. 5.a.

The "Vertical-Z" specimens have, in average, a slightly lower yield strength $\left(\sigma_{\mathrm{y}}=997 \mathrm{MPa}\right)$ than the "Horizontal-XY" $\left(\sigma_{\mathrm{y}}\right.$ $=1024 \mathrm{MPa})$ and the "Horizontal-Xv" $\left(\sigma_{\mathrm{y}}=1063 \mathrm{MPa}\right)$ specimens.

With respective strains to failure of $8.8 \%$ and $7.1 \%$, the "VerticalZ" and "Horizontal-Xv" specimens exhibit a rather ductile behavior. This can be observed in the fractography shown in Fig. 5 . $\mathrm{b}$, the small dimples being typical of ductile fracture.

The "Horizontal-XY" specimens, on the other hand, are characterized by a much lower strain to failure (2\%). Fractography reveals the presence of unmelted areas in the material (Fig. 5.c). These voids are present at the inside edge of the contours.

\subsection{Heat treated specimens: microstructure}

The columnar morphology of the parent $\beta$ grains is essentially not modified by heat treatments below the transus $\left(950^{\circ} \mathrm{C}\right)$. However, this type of treatment induces coarser $\alpha$ lamellae (average width of $2.9 \pm 0.2 \mu \mathrm{m}$ ) in the case of slow cooling (Fig. 6), with some taking a globular aspect (Fig. 6.b). The microstructure obtained after air cooling is very similar to that of as-built material, in terms of $\alpha$ lamellae width ( $1.8 \pm 0.2 \mu \mathrm{m}$, in average).

Heat treatments above the transus $\left(1040{ }^{\circ} \mathrm{C}\right)$, on the other hand, induce major changes in the alloy's microstructure (Fig. 7). The parent $\beta$ grains become much larger, with diameters up to more than $1 \mathrm{~mm}$, and adopt an equiaxed morphology. The aspect of the $\alpha$ lamellae is influenced, to a large extent, by the cooling rate. Fast cooling leads to the formation of acicular $\alpha$ lamellae, consisting in long, needle-like plates. In the case of slow cooling, an almost continuous $\alpha_{G B}$ layer can be observed at the prior $\beta$ grain boundaries. Colonies appear to have nucleated along this $\alpha_{\mathrm{GB}}$ layer 


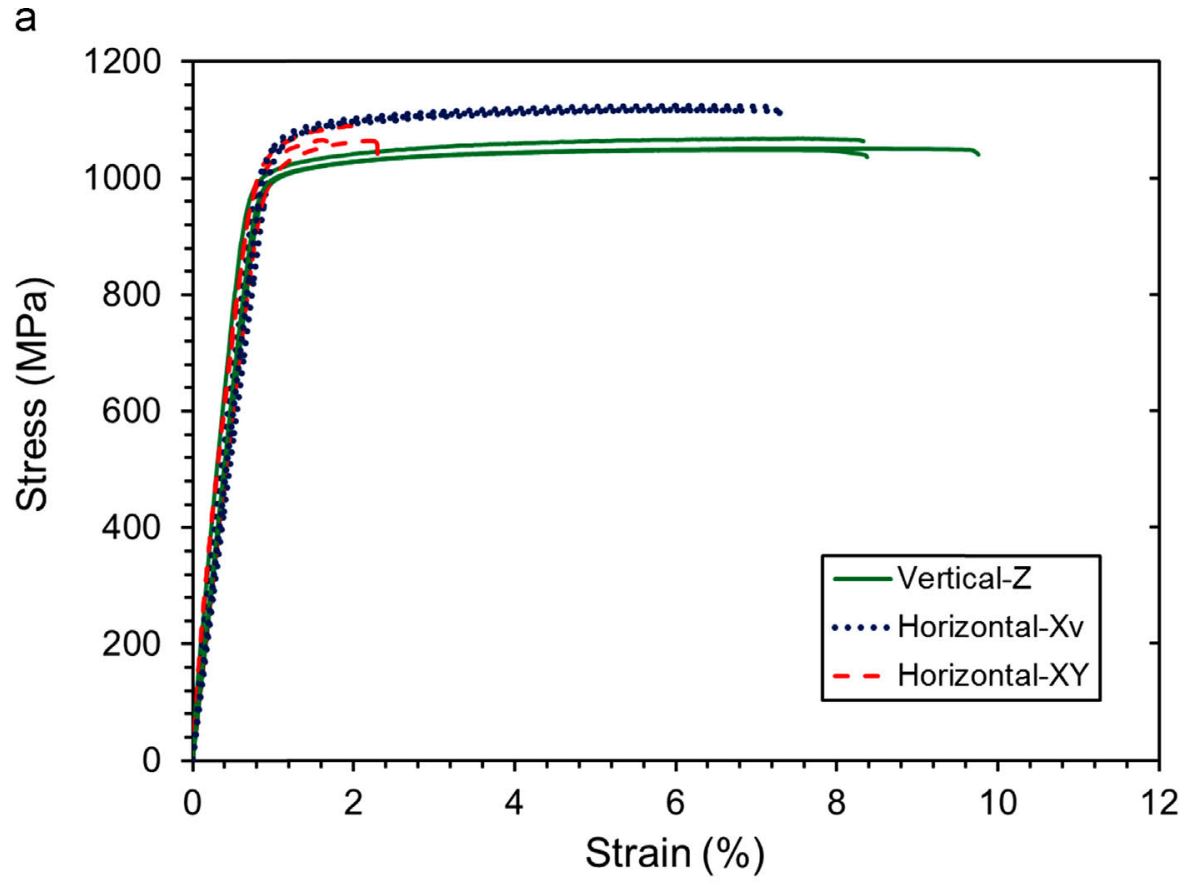

b

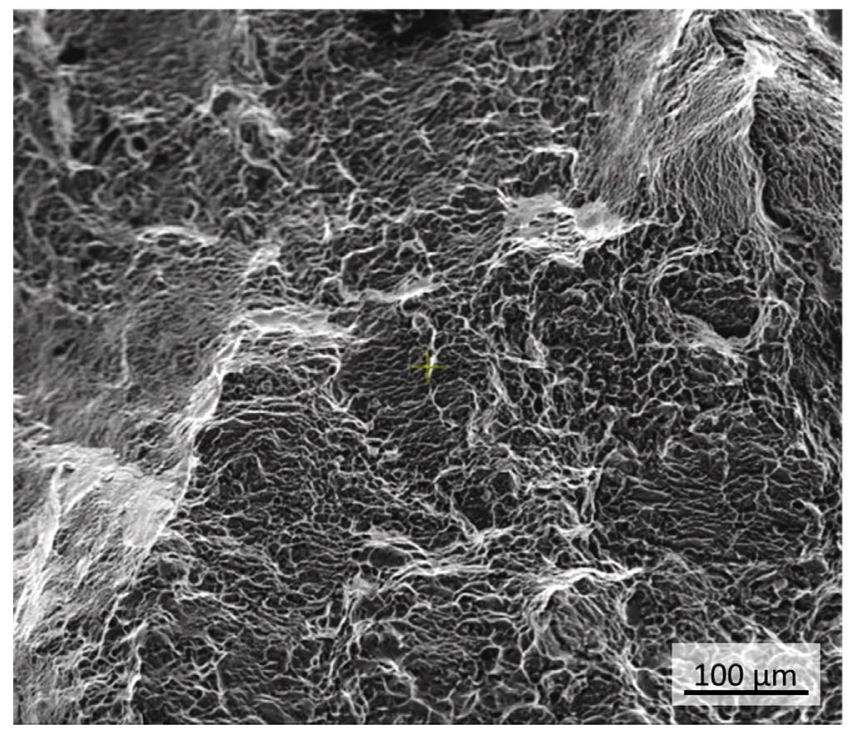

C

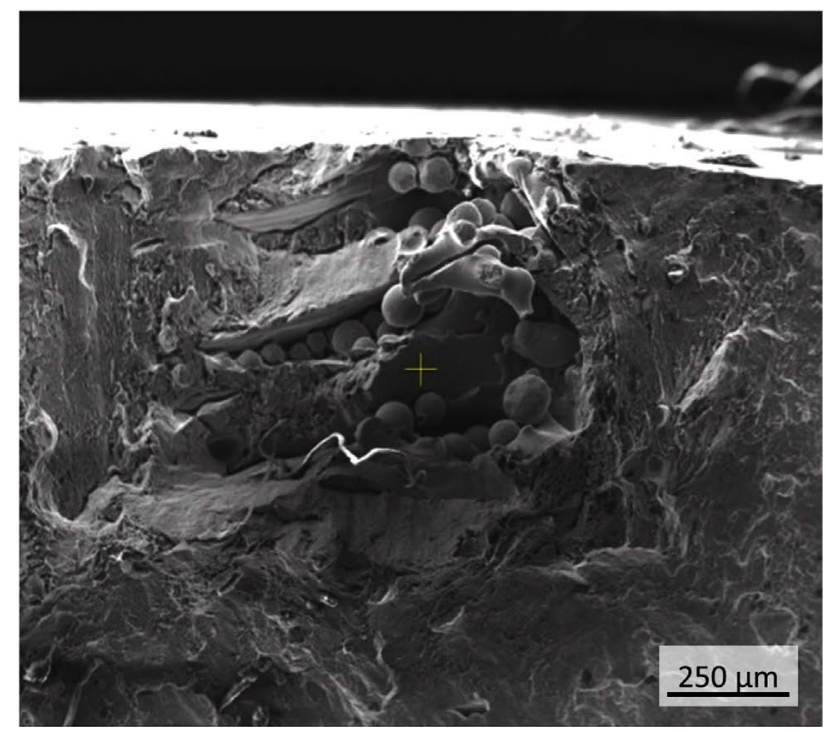

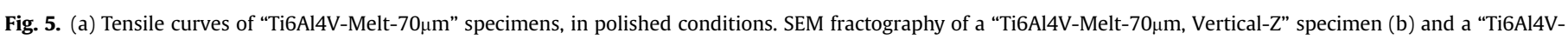
Melt-70 $\mu \mathrm{m}$, Horizontal-XY” specimen (c).

and grown within the $\beta$ grains. These colonies are large: they contain many adjacent $\alpha$ plates, and their length is limited by the size of the parent $\beta$ grain they originate from. The width of these colonies and the small amount of subcolonies - i.e. colonies that nucleate at the boundaries of other $\alpha$ colonies rather than at the $\beta$ grain boundaries - are typical of slow cooling rates.

X-ray diffraction was performed on as-built and heat-treated cubes (Fig. 8.a). A (110) $\beta$ peak can be clearly observed in the specimens heated at $950{ }^{\circ} \mathrm{C}$, i.e. below the transus, especially in the case of furnace cooling. However, this peak is very diffuse in the specimen maintained at $1040{ }^{\circ} \mathrm{C}$ for $30 \mathrm{~min}$ and air cooled and cannot be observed in the case of a furnace cooled specimen heated at $1040{ }^{\circ} \mathrm{C}$. The absence of any significant angular shift between air-cooled and furnace-cooled specimens indicates that no martensite is present in air-cooled specimens, whether they were cooled from a subtransus or a supertransus temperature.
EBSD mapping, reported in Fig. 8.b, was also performed on each of the heat-treated specimens. The phase distribution images confirm qualitatively the results of the XRD spectrum, with higher amounts of $\beta$ (in green) being observed in the specimens treated at $950{ }^{\circ} \mathrm{C}$.

\subsection{Heat treated specimens: variant selection at the scale of a parent $\beta$ grain}

According to the Burgers crystallographic relationship, for each of the four $<111>_{\beta}$ directions, three $\alpha$ variants can be generated, resulting in a total of $12 \alpha$ variants. In Fig. 9, $\alpha$ variants sharing the same $[111]_{\beta}$ direction are highlighted in the same - random color. Fig. 9 reveals a tendency for these $\alpha$ variants to group together. This clustering is particularly significant in the case of specimens treated at $1040{ }^{\circ} \mathrm{C}$ and air cooled, as shown in Fig. 9.b, with some parent $\beta$ grains containing only three $\alpha$ variants, all 
a
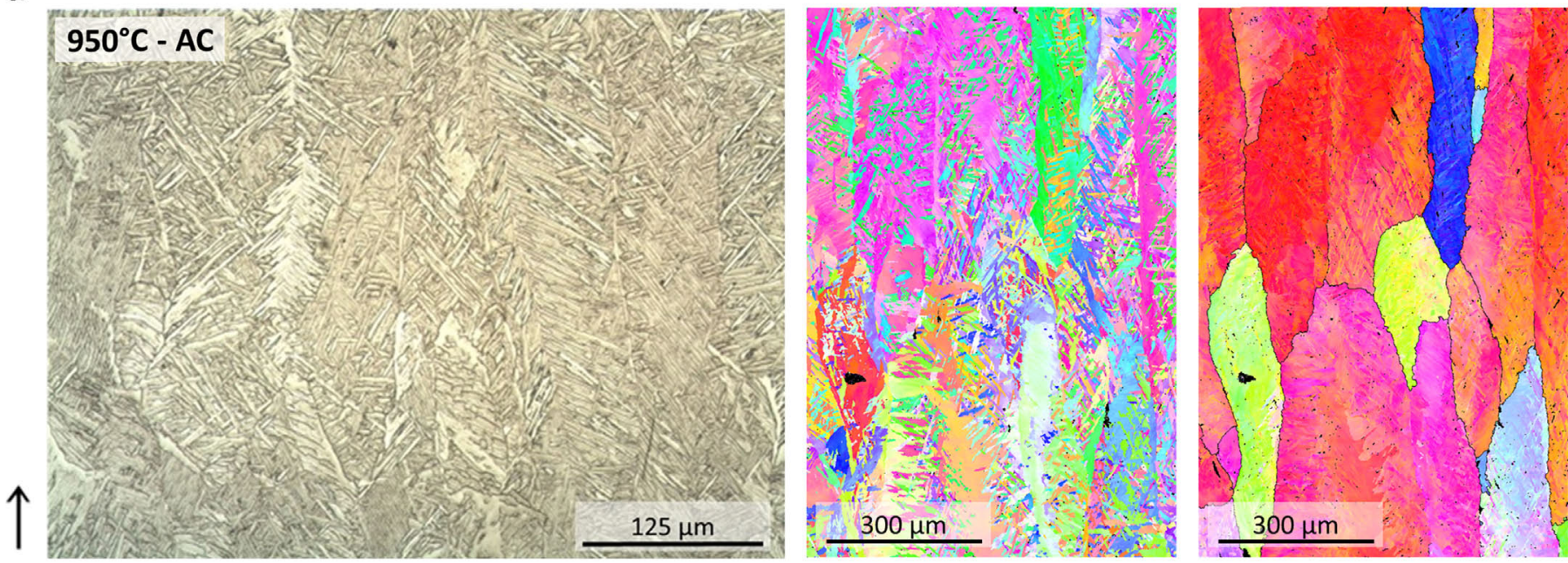

b
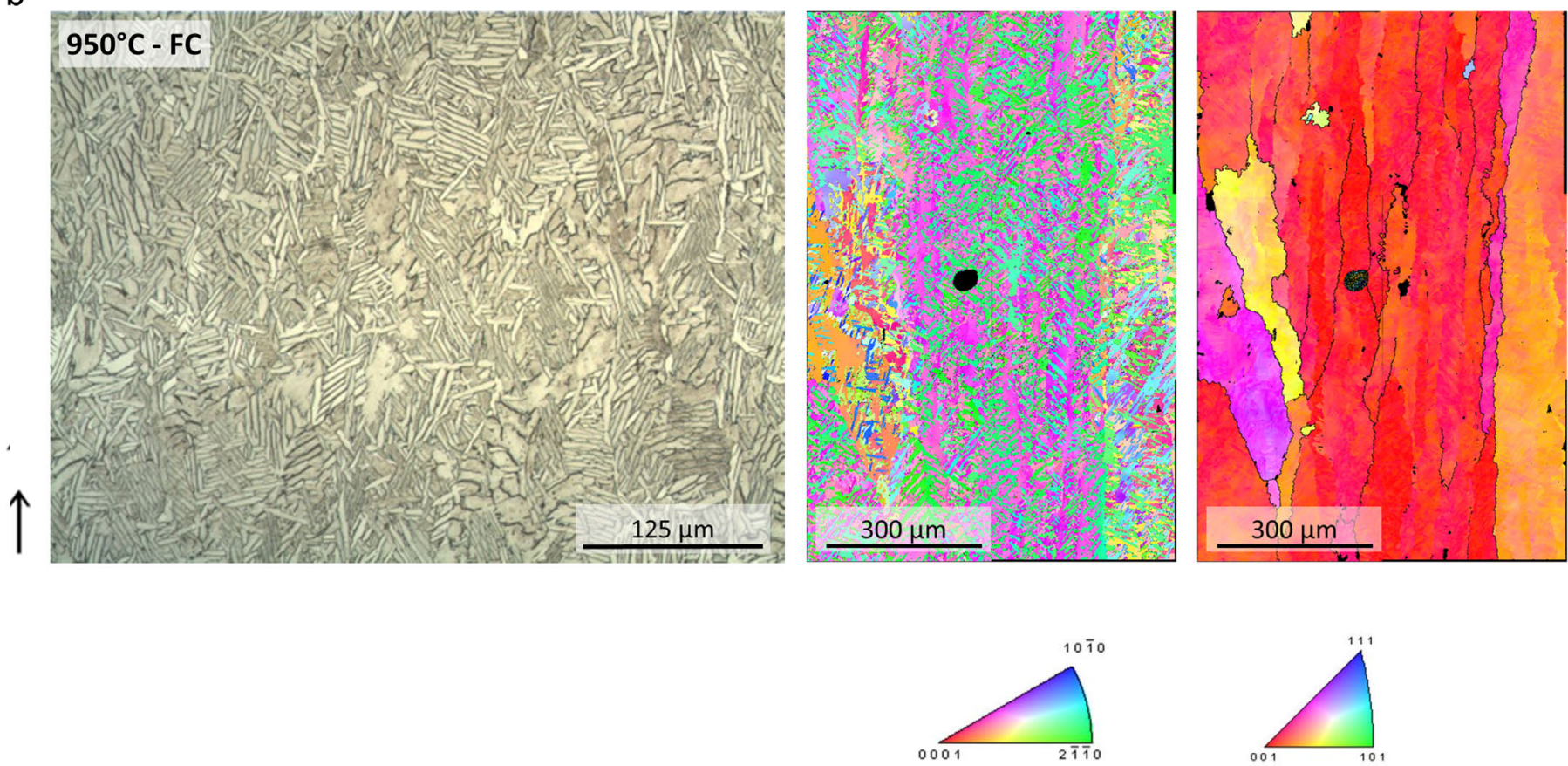

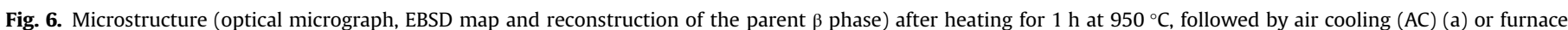
cooling (FC) (b). The direction chosen as reference for the IPF color code is the $Z$ axis defined in Fig. 1, i.e. the build direction.

sharing the same $[111]_{\beta}$ direction. However, no clustering is observed in specimens treated at $1040^{\circ} \mathrm{C}$ and furnace cooled.

The specimens treated at $1040^{\circ} \mathrm{C}$ and furnace cooled exhibit another type of variant selection. Several colonies - i.e. parallel $\alpha$ plates belonging to the same variant of the Burgers relationship appear to have nucleated along $\alpha_{G B}$ layers and grown within the $\beta$ grains. As illustrated in Fig. 10, the crystallographic orientation of these colonies is identical to that of the $\alpha_{G B}$ layer they originate from - highlighted by arrows. This indicates the occurrence of variant selection at the grain boundaries.

\subsection{Heat treated specimens: mechanical properties}

Tensile tests were performed on as-built and on heat-treated specimens. The results are reported in Fig. 11.

A yield strength $\sigma_{y}$ of $830 \mathrm{MPa}$ and a strain to failure of $6.2 \%$ are measured in the case of as-built specimens. Heat treatments lead to lower yield strengths, especially when furnace cooling is applied. Regarding ductility, furnace cooled specimens exhibit a strain to failure $1-2 \%$ higher than that of as received samples. However, air cooled specimens treated above the transus are characterized by a much lower strain to failure. The subtransus heat treatment combined with air cooling has barely no influence on the tensile behavior of the material.

Fractographies performed on supertransus heat-treated specimens are presented in Fig. 11. In air-cooled specimens, fracture occured preferentially along the needle-like $\alpha$ lamellae, in a brittle way (Fig. 11.b). In the case of furnace cooling, a more ductile behaviour can be observed, with the presence of small dimples. Analysis of the fracture profile reveals that the fracture path followed either the boundaries of prior $\beta$ grains or those of $\alpha$ colonies (Fig. 11.c).

The specimens treated below the transus exhibit a typical ductile fracture surface, with small dimples. Fracture occurred preferentially along the $\alpha$ grain boundaries (Fig. 11.d). 
a
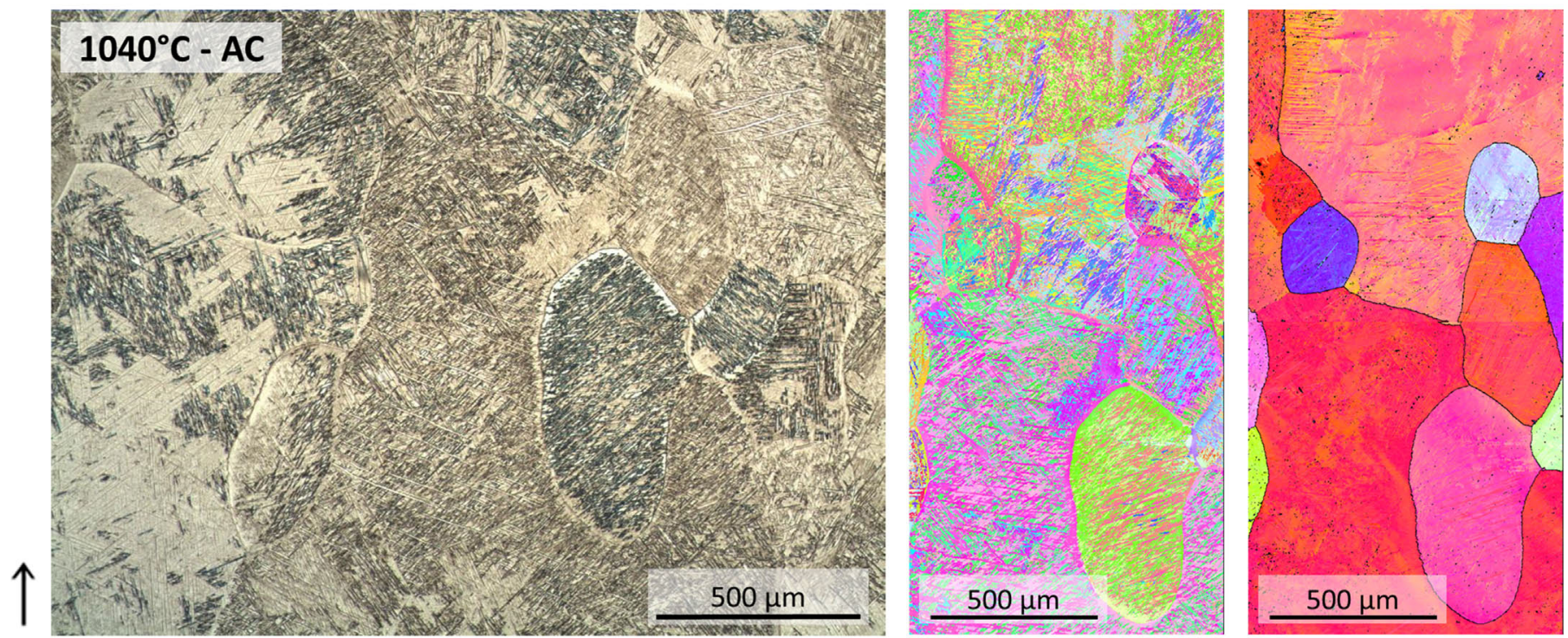

b
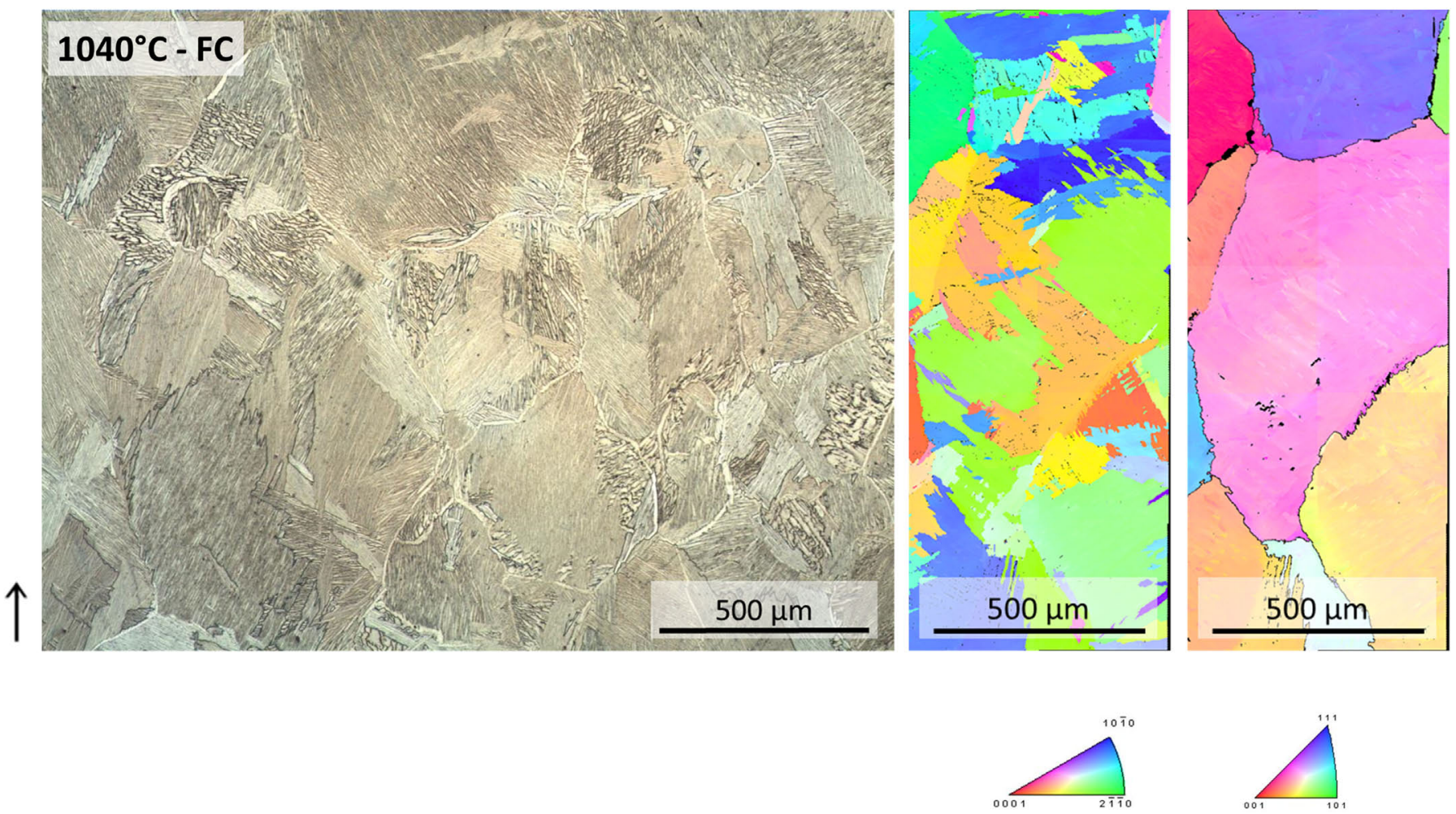

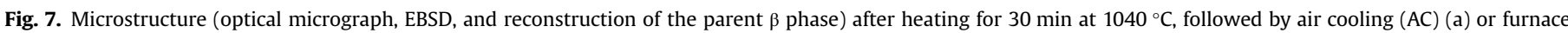
cooling (FC) (b). The direction chosen as reference for the IPF color code is the $Z$ axis defined in Fig. 1, i.e. the build direction.

\section{Discussion}

\subsection{Microstructure and texture of as-built specimens}

As described by several authors [5-7,22], the microstructure of electron beam melted parts is lamellar, with fine $\alpha$ platelets resulting from rapid cooling from the high-temperature $\beta$ phase. The presence of an $\alpha_{\mathrm{GB}}$ layer along some grain boundaries of the prior $\beta$ phase is indicative of the diffusive nature of the $\beta \rightarrow \alpha$ transformation. In that way, the microstructure observed in EBM parts differs from the one obtained in other additive manufacturing processes such as SLM, in which extremely fast cooling rates result in a diffusionless martensitic $\beta \rightarrow \alpha^{\prime}$ transformation [16,19,23,24].

The texture of the parent $\beta$ phase in EBM material (Fig. 3.f) is characterized by the presence of a strong $<001>_{\beta}$ pole in the build direction. This was previously reported by Al-Bermani [6] et al. and Antonysamy et al. [5]. The $<001>$ direction is known to be the favored growth direction during solidification in cubic crystals. Therefore, this direction tends to be aligned with the direction of the maximal thermal gradient in the material, i.e. perpendicularly to the surface of the melt pool. As a result, $\beta$ grains grow preferentially with a $<001>$ orientation parallel to the 


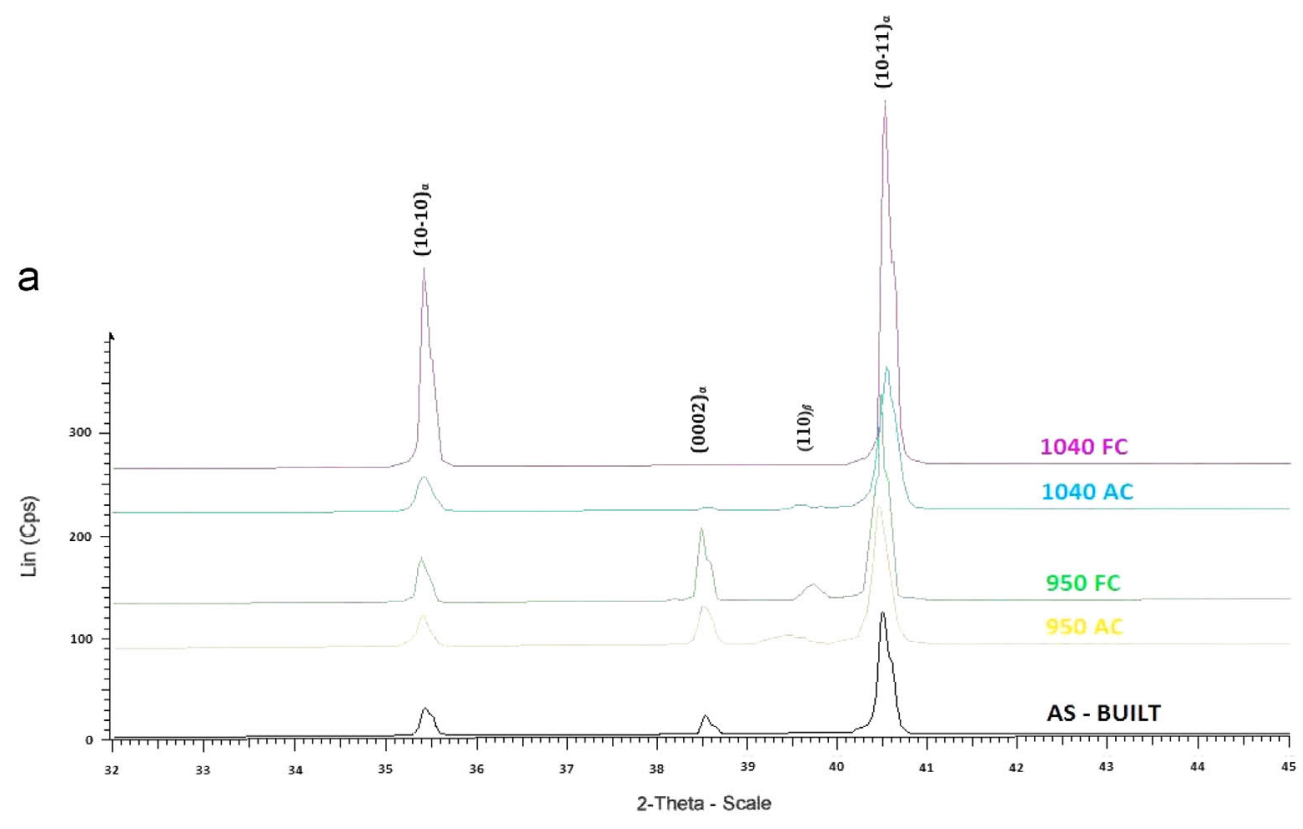

b
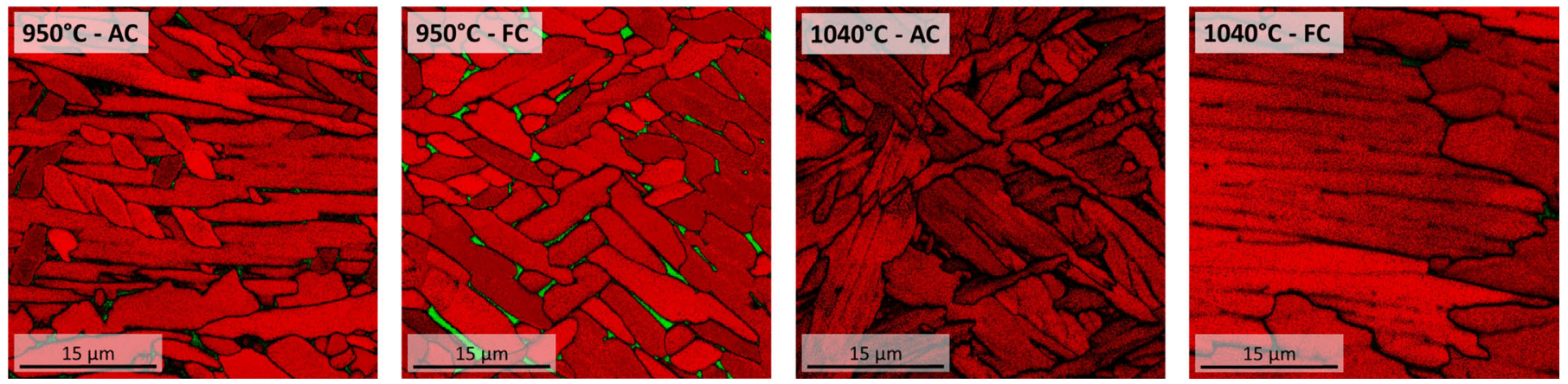

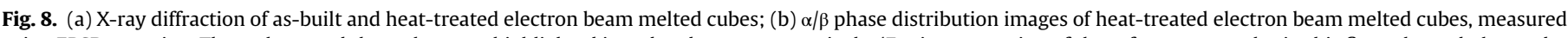

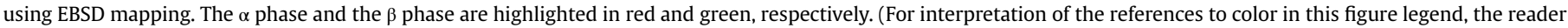
is referred to the web version of this article.)

build direction $\mathrm{N}_{\mathrm{z}}$ [5].

The two other (001) directions tend to be aligned with the $x$ and $y$ axes, which happen to be the two directions alternatively followed by the electron beam during the melting of successive layers of powder. According to Antonysamy et al. [5], this raster pattern induces, in the plane of each layer, a thermal gradient in the $x$ and $y$ directions, alternatively. Therefore, grains expand laterally along this thermal gradient, with a $<001>_{\beta}$ orientation parallel to the two orthogonal $x$ and $y$ raster directions. This can result in the development of a cube component in the texture [5], as in Fig. 3.f. However, this cube component is not systematically observed. Indeed, Antonysamy et al. [5] reported that the $\beta$ phase can adopt alternatively a cube or a fiber texture, depending on the build height of the section.

In order to understand the origin of the variations in texture reported in the literature, texture was analyzed locally by performing EBSD - and subsequent reconstruction of the parent $\beta$ phase - on the cross-section of several samples and at various build heights. As previously observed in Fig. 3.b and .d, each of these EBSD scans contains several clusters in which adjacent $\beta$ grains are weakly misoriented $\left(<15^{\circ}\right)$. A detailed analysis of the texture of each cluster was performed. A typical example is illustrated in Fig. 12. From this analysis, it appears that each individual cluster typically exhibits either a cube texture, aligned with the $x$ and $y$ axes (such as that of clusters 4 and 5 in Fig. 12), or a " rotated cube " texture, in which one $<001>_{\beta}$ axis remains aligned with the buid direction, whereas the two other $<001>_{\beta}$ axes are rotated by a specific angle with respect to the $x$ and $y$ macroscopic directions (cluster 1 being a typical example). Finally, a few clusters (such as cluster 7) exhibit another random type of texture, with no preferential alignment of the $<001>_{\beta}$ axis with the build direction. At a more global scale, these clusters can be considered as a part of the " background " texture.

This local texture analysis tends to indicate the stochastic nature of the formation of either a cube or a fiber texture at a macroscopic scale. Indeed, although most clusters share a common $<001{ }_{\beta} / / \mathrm{N}_{\mathrm{z}}$ orientation - which results in a global texture systematically characterized by a strong pole in the build direction - the other $<001>_{\beta}$ directions are not necessarily oriented along the $x$ and $y$ axes. Texture measurements over larger sections might thus result in the observation of a fiber texture, if many clusters with various " rotated cube " textures are present. On the other hand, if larger or more numerous clusters exhibiting the same cube component - favored by the $x-y$ raster pattern - are in presence, the texture will tend to be more cubic at a macroscopic scale. Due to their relatively important width - typically several hundred $\mu \mathrm{m}$ - the amount of clusters in a cross section is low. As a result, the global texture is highly influenced by the orientation of 


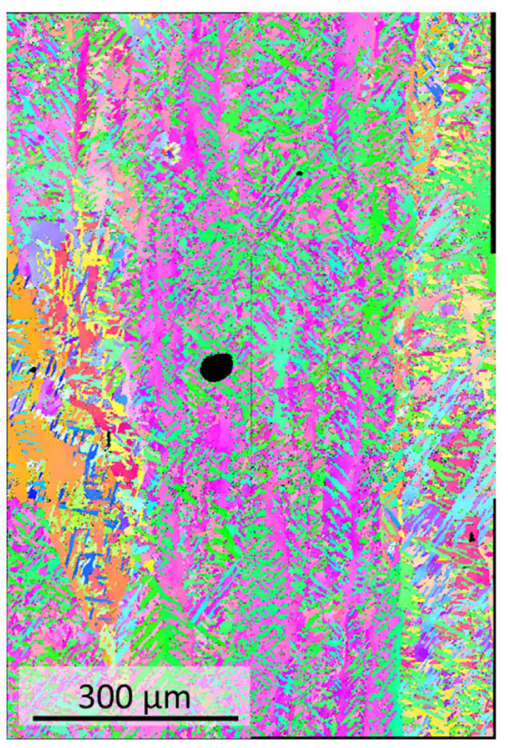

b

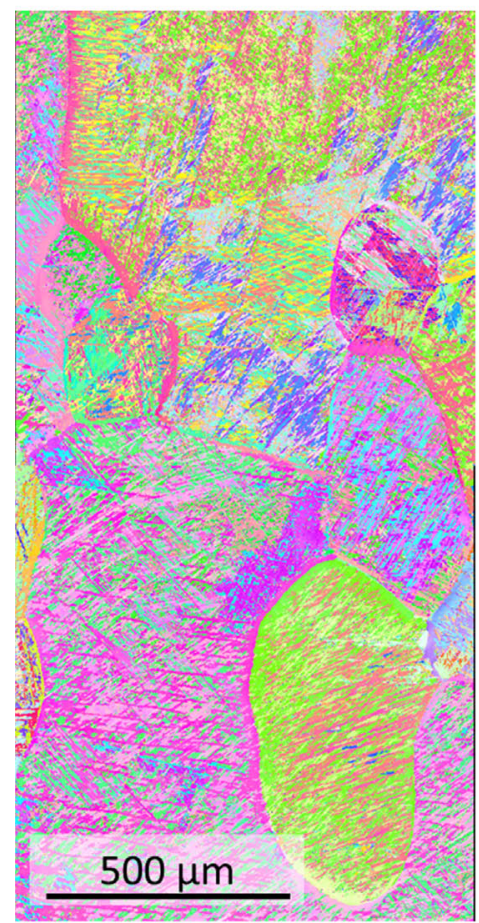

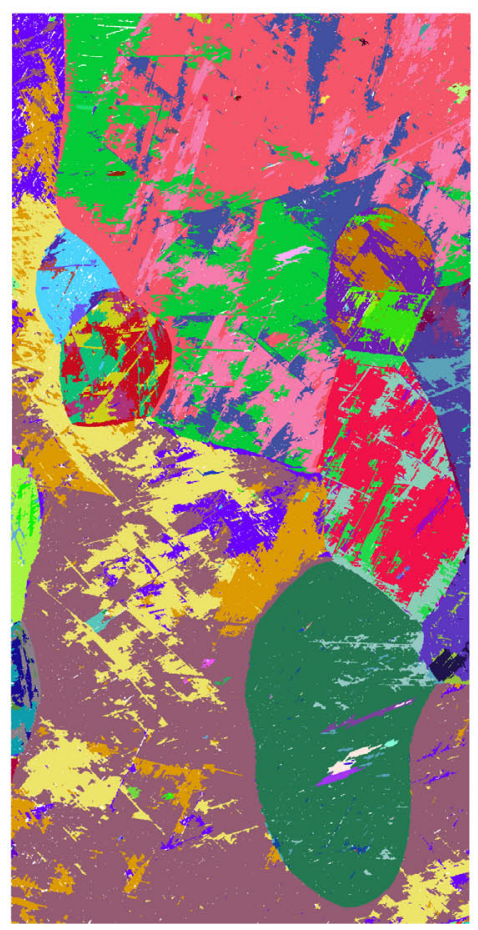

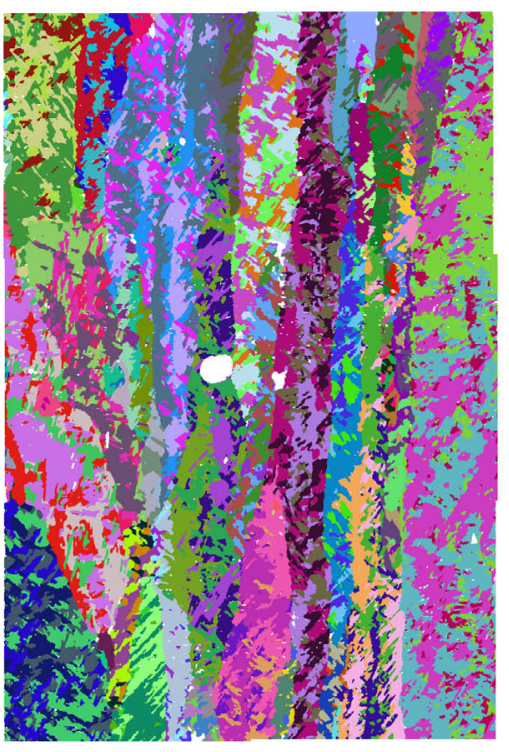

C

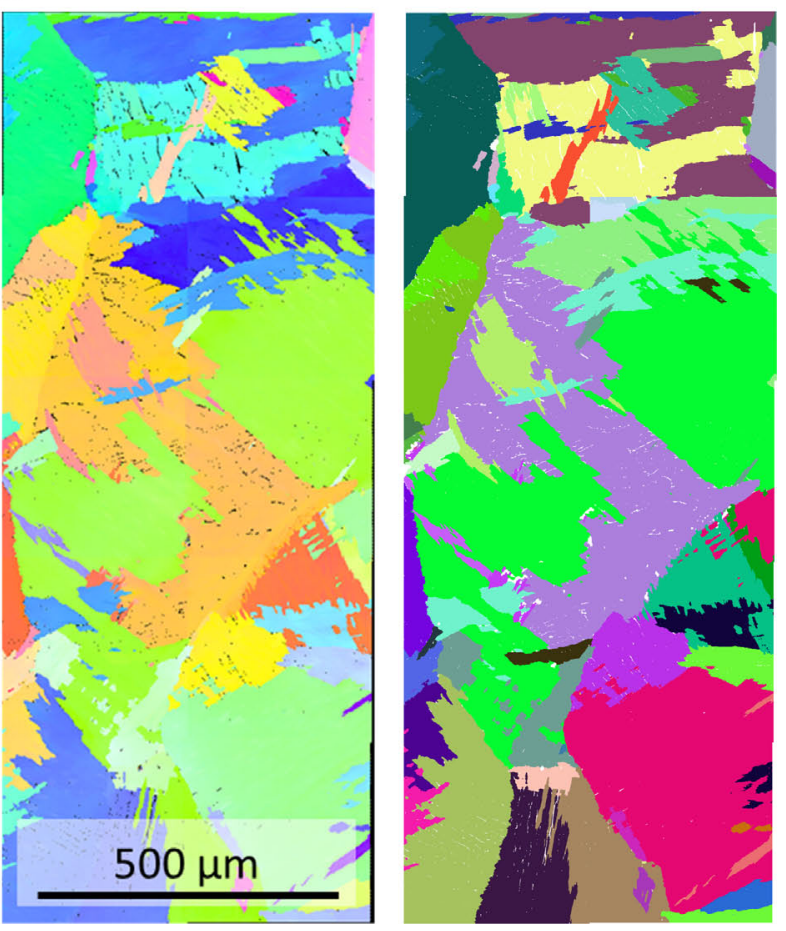

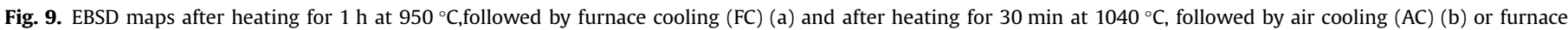
cooling (FC) (c). On the right, variants from the same $[111]_{\beta}$ are highlighted in the same - random - color.

a few clusters, which could randomly lead to the formation of either a cube or a fiber texture.

\subsection{Mechanical properties}

4.2.1. Influence of the build direction on the tensile properties

Tensile tests were performed on specimens built in various orientations in order to determine to what extent the anisotropy of the microstructure was reflected on the mechanical properties. Polished specimens built vertically had a slightly lower yield strength than those built horizontally (Fig. 5). This is in agreement with a tendency previously observed by some authors, for both EBM $[8,13]$ and SLM parts $[8,16]$. Other authors, however, did not observe such a trend [10]. Considering that the "Vertical-Z" and "Horizontal-Xv" specimens were polished and free of defects, this disparity in mechanical behavior can be attributed neither to a difference in surface finish, nor to a different defect distribution between horizontal and vertical specimens. It might thus originate from the anisotropic microstructure and texture, characteristic of electron beam melted materials. This anisotropy, which is very marked at high temperature, due to the columnar morphology of the $\beta$ grains, is less significant in the processed material - a consequence of the $12 \alpha$ variants generated during the $\alpha \rightarrow \beta$ transformation. The resulting weak anisotropy explains the overall limited deviations in properties with build orientation. 
a

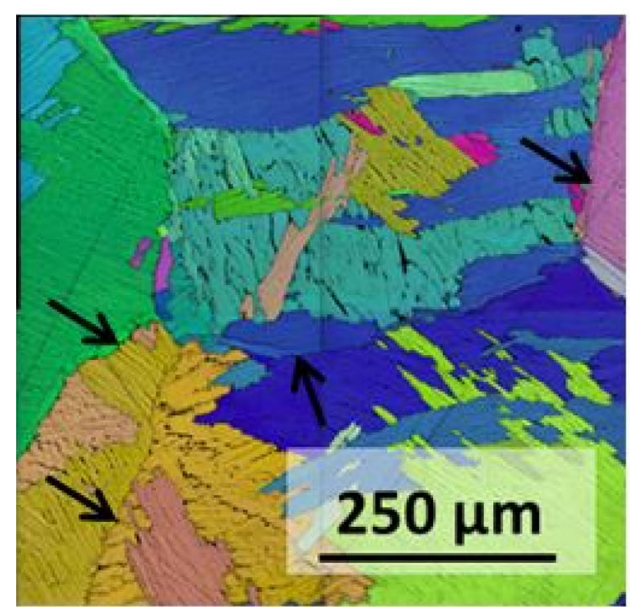

b

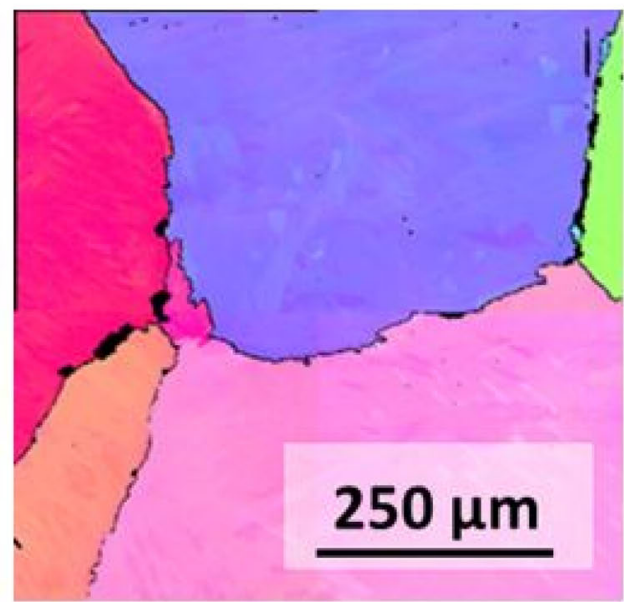

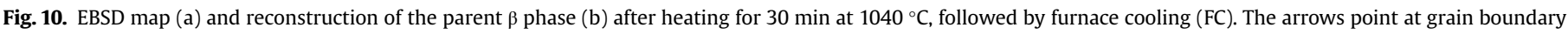
$\alpha_{\mathrm{GB}}$ layers exhibiting an orientation identical to that of an adjacent $\alpha$ colony.

\subsubsection{Origin of defects}

The mechanical behavior of the EBM material is also closely related to the presence of critical defects within the parts.

The "Horizontal-Xv" specimens (Fig. 4.b) exhibit a lower strain to failure than the "Vertical-Z" ones (Fig. 4.a), particularly when the "Ti6Al4V-Melt-50 $\mu \mathrm{m}$ " theme is applied. The fractographic analysis of these "Ti6Al4V-Melt-50 $\mu \mathrm{m}$ Horizontal-Xv" specimens reveals that the melting of the powder was locally insufficient, generating large non-spherical porosities. Such critical defects induce premature failure. As highlighted by other authors [25,26], these non-spherical porosities are a consequence of unoptimized process parameters. In this study, the high amount of defects present in the "Horizontal-Xv" specimens - compared to the "Vertical-Z" specimens - can be attributed to the fact that the scan length is much longer in the case of "Horizontal-Xv" specimens. In order to build defect-free parts, scan lengths longer than $100 \mathrm{~mm}$ should be avoided. This is advised by Arcam $A B^{\circledR}$, based on their internally developed thermal meta-model. This built-in tool first determines the current required at the processed layer to maintain an adequate surface temperature, taking into account energy losses caused by radiation and conduction. To keep the melt profile constant, this current is then adjusted in function of the scan line length, with longer scan lengths requiring higher current. However, there is a physical limit to the melting current, above which the beam spot quality deteriorates rapidly. If the scan line length is too long ( $>100 \mathrm{~mm}$ ), the required current cannot be reached, resulting in insufficient energy input and therefore in poor melting. The orientation in the build chamber of parts with a dimension exceeding $100 \mathrm{~mm}$ should be chosen in a way that minimizes scan line lengths. Alternatively, the parts should be printed into sections which do not have scan line lengths that are too long, with the "Melt Model Wise" function turned ON. When this function is activated, each section is melted independently from the others, dividing the total scan line length into shorter segments.

In the "Ti6Al4V-Melt-70 $\mu \mathrm{m}$ Horizontal-XY" specimens, which exhibit a very low strain to failure, voids located at the boundary between the contour of the part and the bulk were observed. The exact origin of these defects remains unknown. The presence of such irregular defects preferentially in the contour region of the sample was also observed by Tammas-Williams et al. [26]. They attribute it to the contouring parameters employed by Arcam, which differ from the hatching, potentially leading to lack of fusion between layers. However, the fact that these defects were only observed for the "Horizontal-XY" specimens highlights the influence not only of the process parameters, but also of the part orientation on the defect population. These porosities might indeed be favored by excessive heat losses from the parts to the build table, caused by the many supports - acting as heat sinks - located below these horizontally built specimens, resulting in a locally insufficient melting of the powder.

From these observations, it appears that the part geometry and orientation in the build chamber, the presence and location of build supports as well as the set of building parameters chosen during the EBM process can all have an influence on the amount and type of defects generated.

\subsubsection{Ductility and oxygen pick-up}

In the case of optimized process parameters, despite the absence of defects in the parts, the ductility remains relatively low (between $4.7 \%$ and $8.8 \%$ ). These results differ notably from the mechanical specifications of dense electron beam melted parts reported by the manufacturer (strain to failure of 16\%) [2].

A possible explanation to this discrepancy would be the pickup of oxygen - for which titanium has a high affinity - by the powder. Oxygen contamination can indeed occur during the stocking, handling and recycling of the powder. Besides, since the EBM build chamber is only pumped out till about $10^{-4}$ torr, some water tends to freeze on the walls. Oxygen pick-up can thus arise from the heating and decomposition of these water molecules during the EBM process itself.

The effect of interstitials such as oxygen on the mechanical properties of titanium is well known [27]. The - elastic, chemical and electrical - interactions between dislocations and solute atoms affect the material's tensile behavior. They increase its yield strength while reducing significantly its ductility. An excessive (i.e. $>0.19 \%$ ) amount of oxygen in the powder could explain the low ductilities measured in this study.

Quantitative measurements of the oxygen content confirmed this hypothesis, by revealing that the amount of oxygen in the electron beam melted parts systematically exceeded 0.23\%. Excessive amounts of oxygen were not only measured in the electron beam melted parts, but also in the recycled powder used to build them.

To avoid this potentially detrimental oxygen contamination, precautions should be taken during the use of the powder, and systematic quality control of the powder should be implemented. Recycling of the powder should be limited, considering that the oxygen content increases as the powder is being handled and 
a

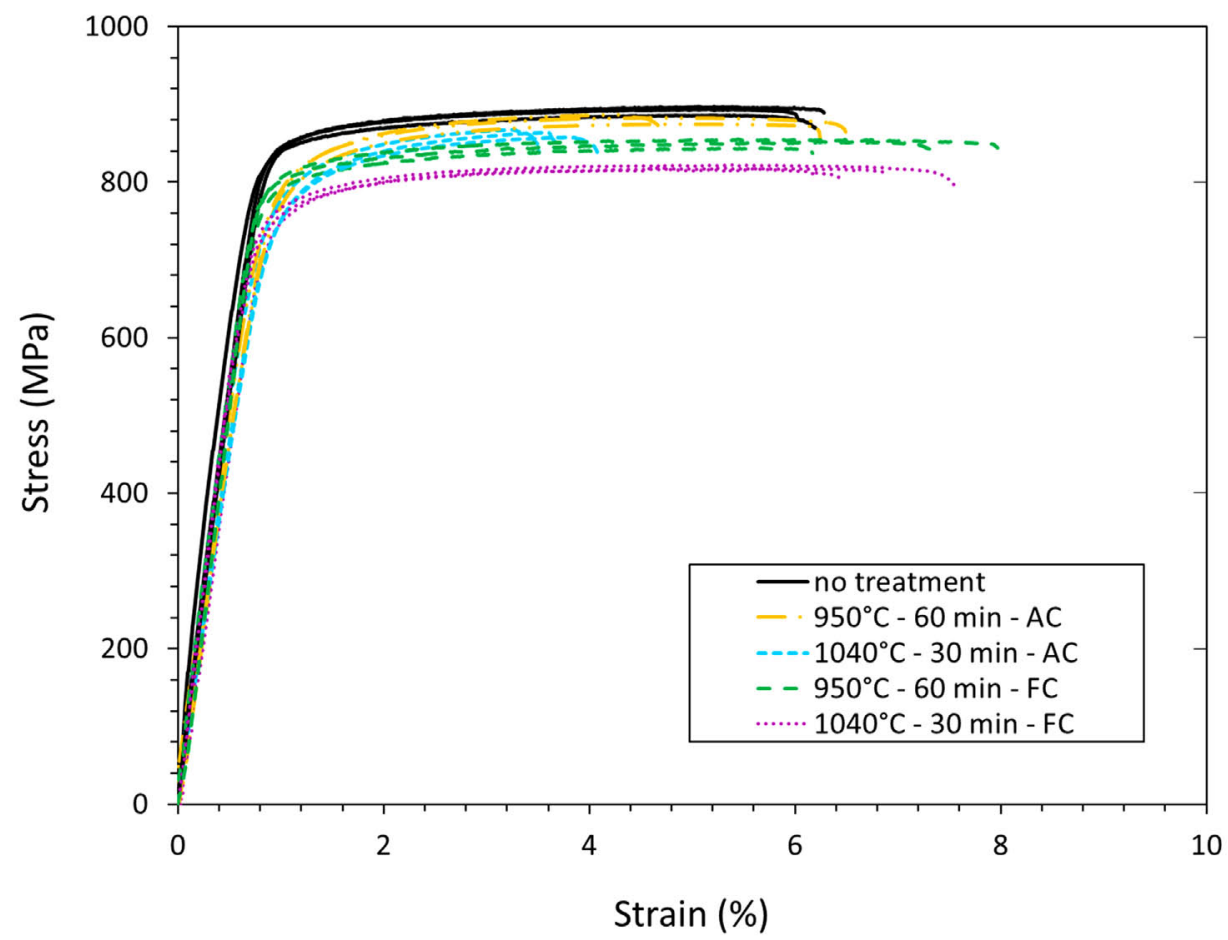

b
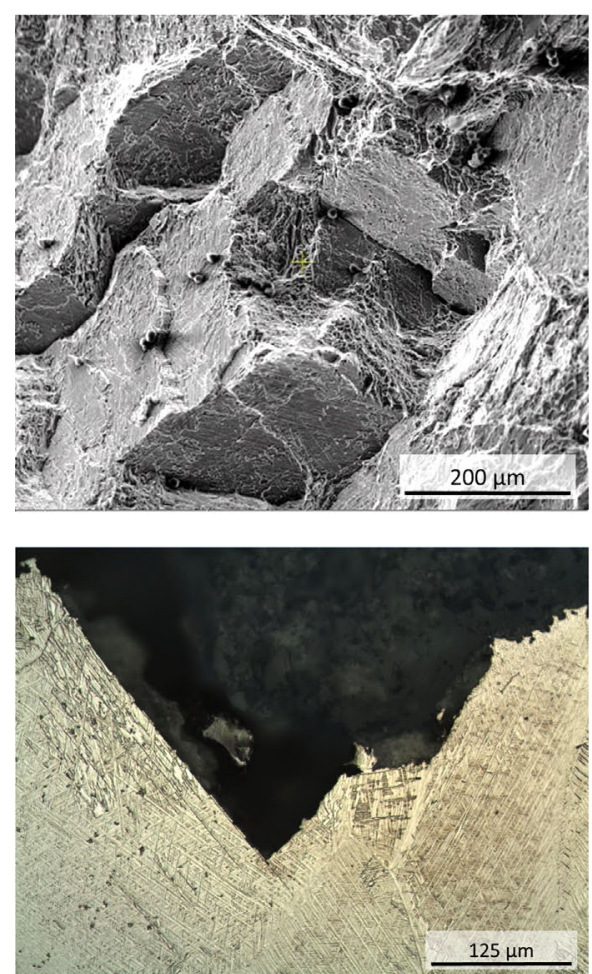

C
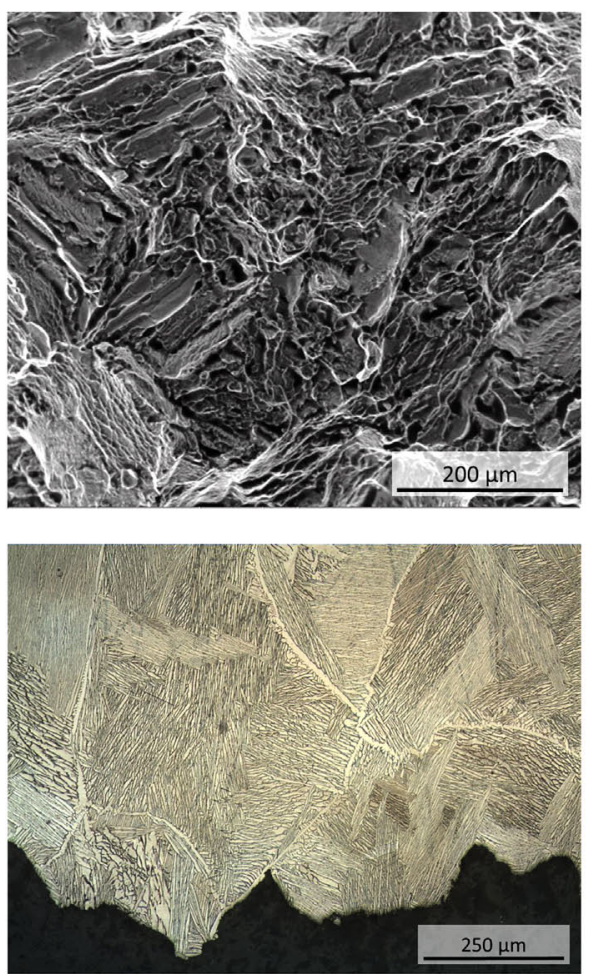

d
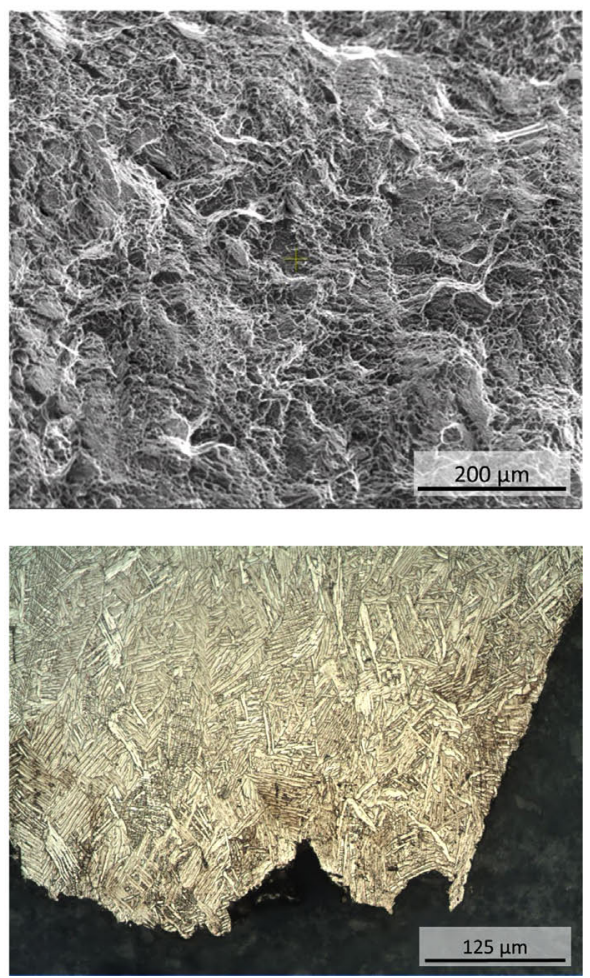

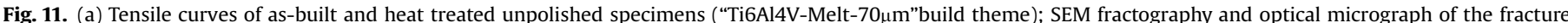

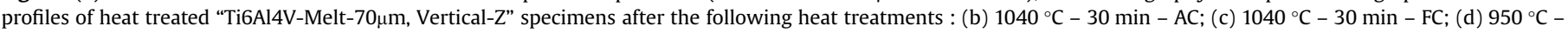
$30 \mathrm{~min}-\mathrm{AC}$.

recycled, as highlighted by $\operatorname{Arcam} \mathrm{AB}^{\circledR}[20]$.

\subsubsection{Effect of mechanical polishing}

Another factor that appears to have a substantial influence on the mechanical behavior of an electron beam melted part is its surface finish. Compared to as-received specimens, polished specimens exhibit higher strain to failure. This can be explained by the mechanical removal of critical non-spherical porosities, many of which are present near the surface of the sample. Such defects induce stress concentration and act preferentially as crack initiators. Due to the lower amount of defects they contain, polished specimens have a higher ductility than as-built ones. 
cluster 3

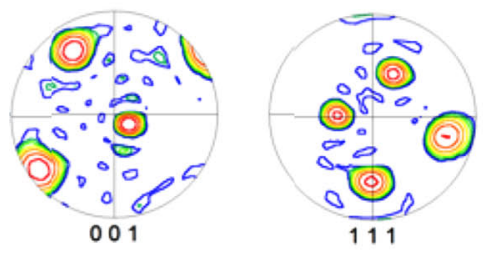

\section{cluster 2}
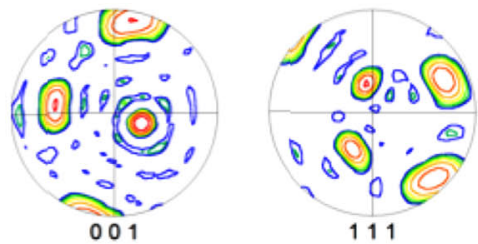

\section{cluster 1}

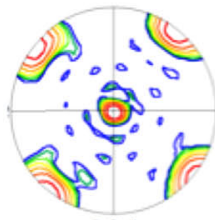

001
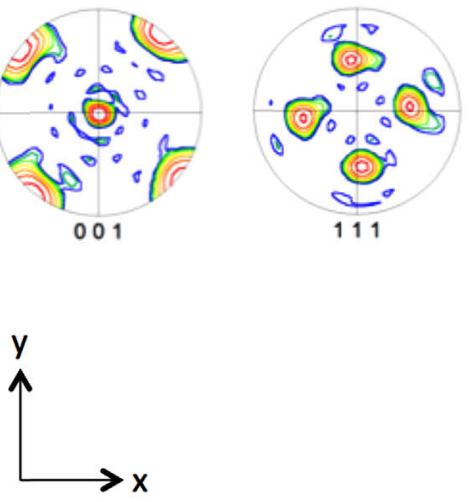

cluster 4
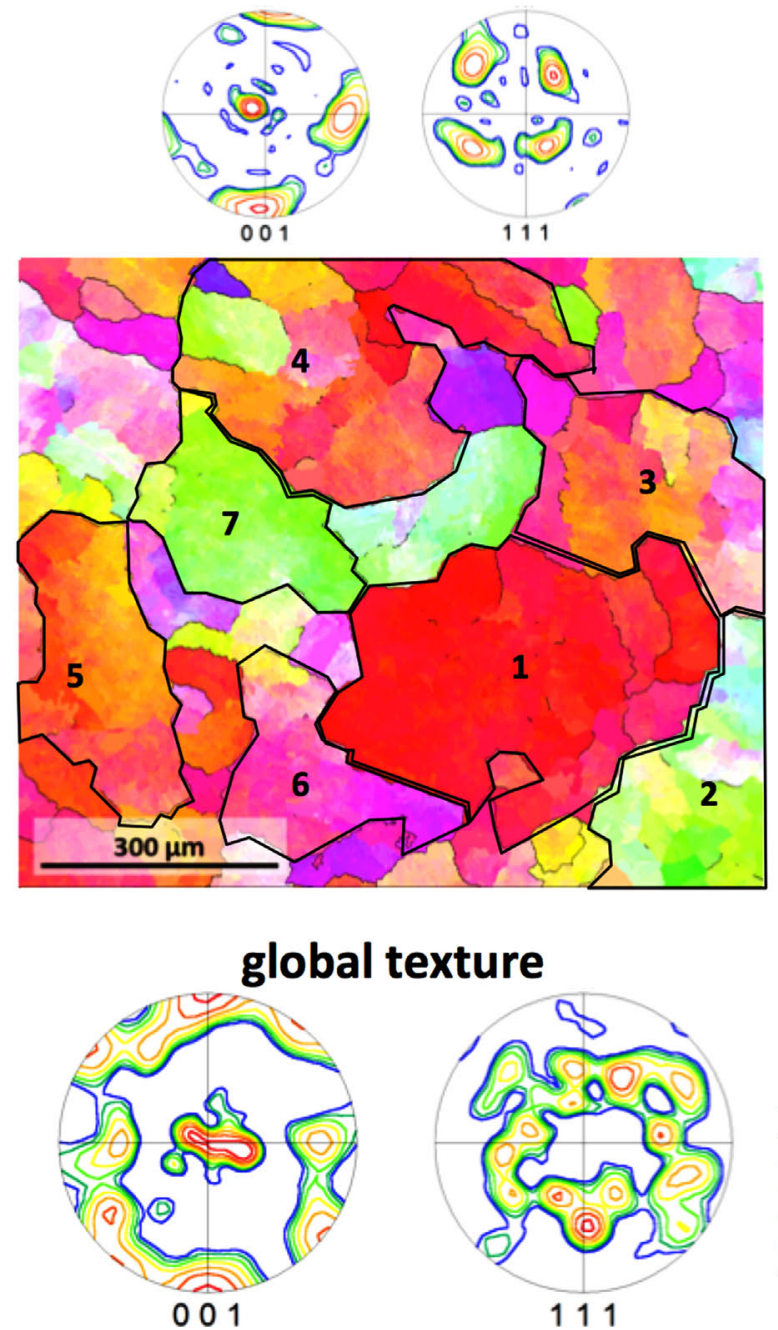

cluster 5

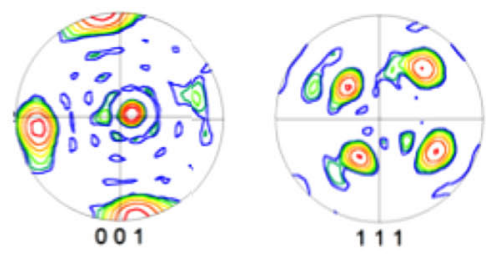

\section{cluster 6}
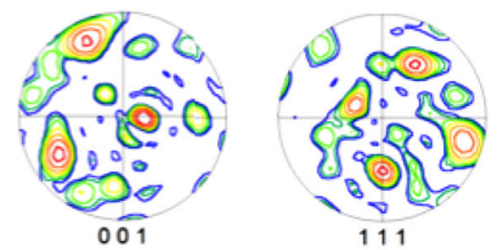

cluster 7
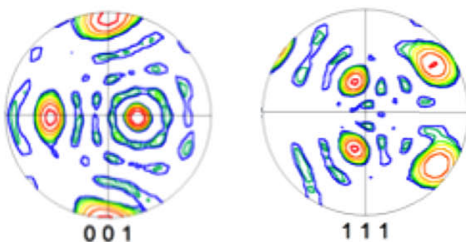

111

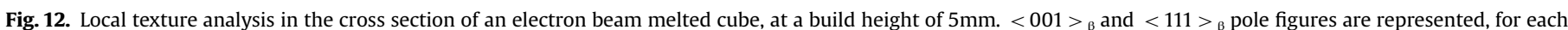
of the seven individual clusters highlighted on the EBSD scan as well as for the totality of the scanned area.

a

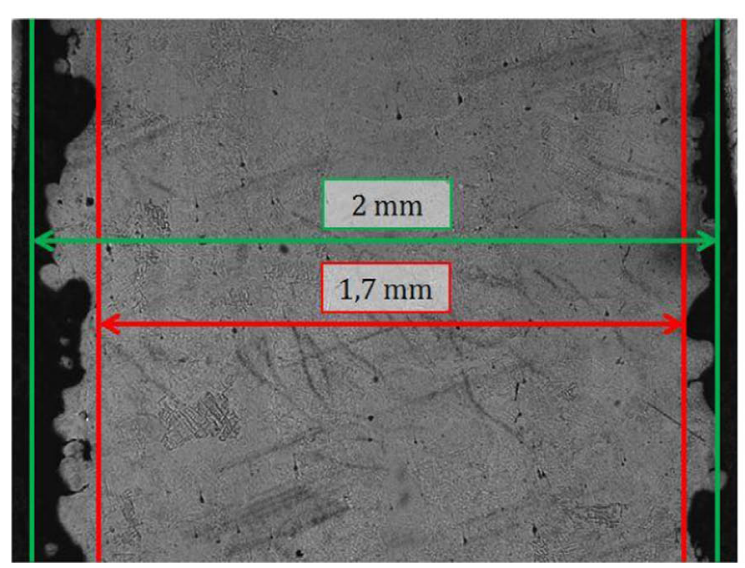

b

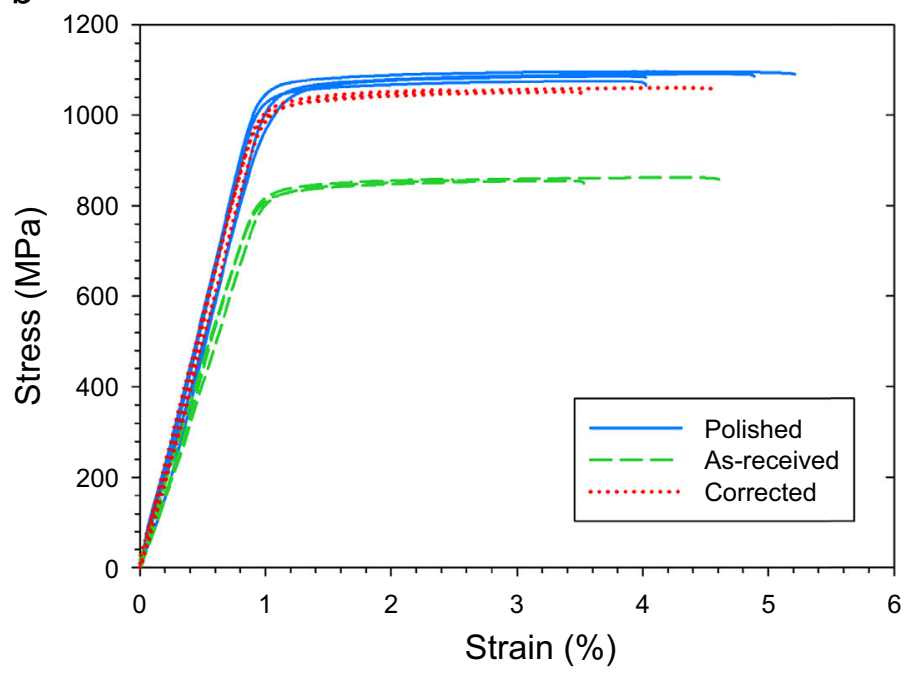

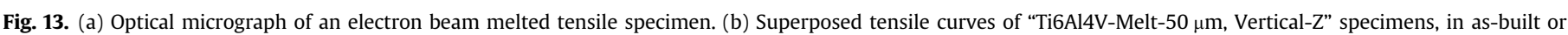
polished condition. The "corrected" curves were computed assuming that the surface layer, typically $150 \mu \mathrm{m}$ thick, does not carry any load. 
The surface finish also appears to have an important influence on the yield strength measurement. As illustrated in Fig. 13, the surface of electron beam melted specimens is characterized by a high roughness, caused by the sintering of powder that occurs during the process. At the surface, a $\sim 150 \mu \mathrm{m}$ thick layer can be considered as mechanically inefficient, due to the low and irregular amount of matter it contains. In other words, if we consider a $2 \times 6 \mathrm{~mm}^{2}$ section, it can be assumed that only $1.7 \times 5.7 \mathrm{~mm}^{2}$ effectively support the load and contributes to the strength of the specimen. Under this assumption, and for this particular geometry, the measured or apparent yield strength of as-built specimens should be increased by $23 \%$ so as to obtain the actual or intrinsic yield strength of the material. This theoretical calculation was applied on the data measured on as-built tensile specimens. The resulting corrected tensile curves are shown in Fig. 13. The tensile curves measured on polished specimens are also depicted in Fig. 13. The mechanical polishing was sufficient to remove entirely the $\sim 150 \mu \mathrm{m}$ surface layer. The corrected curves are in very good agreement with the results obtained on polished specimens. This validates the assumption that the $150 \mu \mathrm{m}$ thick layer does not support the load applied on the specimen. This observation is particularly crucial in the production of small objects or fine cellular structures, in which the proportion of mechanically inefficient matter becomes critical [28].

\subsection{Influence of post heat treatments}

Thermal post-treatments induce microstructural changes, which in turn affect the mechanical properties.

\subsubsection{Microstructure evolution}

Subtransus heat treatments have a limited impact on the microstructure of the material. The columnar morphology is maintained, and the width of the $\beta$ columns observed in untreated EBM parts remains unchanged. It is indeed known that below the transus, the growth of the $\beta$ phase is hindered by the presence of the $\alpha$ phase [29]. At $950{ }^{\circ} \mathrm{C}$, the last remainders of primary $\alpha$ are located preferentially along the boundaries of the $\beta$ columns [30]. Here, widening of the columns is impeded by this remaining $\alpha_{\mathrm{GB}}$ layer. Therefore, $\beta$ grain growth does not occur at this temperature, resulting in very limited microstructural changes. Only the width of the $\alpha$ lamellae appears to be modified by such treatments, depending on the cooling rate applied. Slow cooling leads to microstructural coarsening, as shown in Fig. 6, and allows the $\beta$ phase to be retained along the $\alpha$ lamellae boundaries and preferentially at the triple points of the $\alpha$ lamellae. This can be clearly seen in Fig. 8.b and is confirmed by the relatively high $(110)_{\beta}$ peak present in the XRD spectrum (Fig. 8.a). Similar observations were made in the case of HIP'ed parts: Lu et al. report an increase in the presence of the $\beta$ phase from 3\% in as-built condition to $9.5 \%$ after HIP [14]. A hold of the material at high temperature allows the $\beta$ stabilizing elements to diffuse from within the $\alpha$ plates to the $\beta$ matrix situated along the $\alpha$ grain boundaries so that the material reaches a closer-to-equilibrium state.

Above the transus, obstacles to the $\beta$ grain growth are no longer present. Therefore, in the case of supertransus treatments, rapid growth of the $\beta$ grains occurs, leading to the formation of equiaxed $\beta$ grains, which can be up to $\sim 1 \mathrm{~mm}$ large. Upon air cooling, the $\beta \rightarrow \alpha$ transformation leads to the formation of fine acicular $\alpha$ lamellae. When slow furnace cooling is performed, the $\alpha$ phase first nucleates preferentially at the $\beta$ grain boundaries, resulting in the formation of a continuous $\alpha_{\mathrm{GB}}$ layer [31]. Afterwards, $\alpha$ plates nucleate from this $\alpha_{\mathrm{GB}}$ layer and grow into the $\beta$ grains as parallel plates, belonging to the same $\alpha$ colony, i.e. to the same variant of the Burgers relationship. These platelets grow into the prior $\beta$ grain until they meet other $\alpha$ colonies nucleated at other grain boundary areas. The width of these colonies is only limited by that of their respective parent $\beta$ grain. Many of them are larger than $500 \mu \mathrm{m}$.

Depending on the heat treatment applied to the material, two distinctive types of variant selection mechanisms occur.

The first type takes place at the $\beta$ grain boundaries in the case of a heat treatment above the transus followed by slow cooling. Indeed, during such a treatment, a continuous $\alpha_{\mathrm{GB}}$ layer is formed at the $\beta$ grain boundaries. As a result of the relatively low driving force for nucleation, nucleation occurs preferentially along the grain boundary $\alpha_{G B}$ layer. Few sites of nucleation are activated, resulting in few variants being generated. As suggested by Stanford and Bate [32], the colonies nucleating from the $\alpha_{\mathrm{GB}}$ layer have the same orientation. A clear variant selection is thus observed when the $\beta \rightarrow \alpha$ phase transformation takes place in the presence of a $\alpha_{\mathrm{GB}}$ layer.

When faster cooling rates are applied, on the other hand, a variant selection mechanism for intragranular $\alpha$ takes place. In this case, clustering - a tendency for $\alpha$ variants sharing the same $[111]_{\beta}$ direction to group together - is observed. Such a clustering has already been reported for titanium [33]. This clustering is particularly significant in the case of specimens treated at $1040{ }^{\circ} \mathrm{C}$ and air cooled. In some parent $\beta$ grains, the selection of a specific cluster leads to only three $\alpha$ variants being present, all sharing the same $[111]_{\beta}$ direction.

\subsubsection{Effect on tensile properties}

In lamellar microstructures, the parameter that mostly influences the yield strength is the $\alpha$ lamellae - or colony - size, which determines the effective slip length [31]. The microstructural coarsening caused by furnace cooling results in lower yield strengths levels. This decrease in yield strength is more pronounced when furnace cooling is performed on a specimen treated above the transus. In this case, rather than a moderate coarsening of existing $\alpha$ laths, new $\alpha$ lamellae, clustered in large colonies, are generated within the parent $\beta$ grains. The size of these colonies explains the low yield strength observed in furnacecooled samples treated above the transus.

On the other hand, the fine microstructure obtained after air cooling leads to high yield strength levels. In the case of a subtransus heat treatment combined with air cooling, the microstructural changes induced in the material are so limited that the resulting tensile behavior is essentially the same as that of the asbuilt material.

A general information that can be retrieved from the post EBM thermal treatments performed in this study is that they do not lead to very large changes in mechanical performances.

\section{Conclusions}

The results of this study can be summarized as:

(1) The microstructure specific to electron beam melted material results in a slightly anisotropic mechanical behavior. Vertically built tensile specimens exhibit a lower yield strength than those built horizontally. The texture randomization brought about by the phase transformation is - at least partly - responsible for this behavior.

(2) In the case of unoptimized process parameters or inappropriate disposition of the parts in the build chamber, defects tend to be generated. Such porosities are the consequences of a locally insufficient melting of powder. They are particularly detrimental to the ductility of electron beam melted parts. Minimizing the scan length by choosing preferentially a vertical orientation of the part is a way to avoid such detrimental 
porosities.

(3) Dense, defect-free electron beam melted parts are characterized by high yield strength and surprisingly low ductility. This mechanical behavior probably originates from excessive oxygen content in the alloy. To avoid detrimental oxygen contamination, precautions should be taken during the stocking, handling and recycling of the powder.

(4) The sintering taking place at the surface of electron beam melted parts generates a roughness level which is inherent to the EBM process. As a result, a rough surface layer can be systematically considered as mechanically inefficient. For the range of process parameters used in this research, this layer was found to be $\sim 150 \mu \mathrm{m}$ thick. When designing electron beam melted parts, it is crucial to consider this roughness. As already highlighted by previous authors [13], designers should keep in mind that the tensile properties of machined parts might be consistently higher than those of as-built parts. The dimensions should be chosen accordingly. This could even be more critical when fatigue properties are considered.

(5) The microstructure of electron beam melted parts can be modified, to some extent, by post-process heat treatments. However, significant work is still required to define optimum heat treatments for parts obtained by EBM. Indeed, subtransus heat treatments only induce very moderate microstructural changes, resulting in a limited mechanical effect. Supertransus heat treatments, on the other hand, generate substantial microstructural changes. The columnar morphology is transformed into an equiaxed one, resulting in a more isotropic material. However, the fast $\beta$ grain growth that these treatments induce is uncontrollable and mechanically undesirable.

(6) The heat treatments investigated in the present study do not bring about considerable improvement to the mechanical properties of electron beam melted parts. The production of conventionally forged, rolled or extruded Ti alloy parts involve complex thermo-mechanical processing during which different phenomena such as recrystallization and globularization are mechanically induced. Such a mechanical treatment cannot be envisaged in additive manufacturing, at least in its present set-up. Consequently, a potential alternative is a better control of the process itself. Investigating the influence of some key parameters on the microstructure and on the resulting mechanical behavior appears as a promising strategy to eventually optimize the balance between strength and ductility.

\section{Acknowledgments}

The authors are grateful to the F.R.I.A. - F.N.R.S. for financing this research.

\section{References}

[1] J. Hiemenz, Electron Beam Melting, Adv. Mater. Process. (2007) 45-46165 (2007) 45-46.

[2] Arcam. 2014; Available from: 〈http://www.arcam.com/〉.

[3] L.E. Murr, et al., Microstructures and mechanical properties of electron beamrapid manufactured Ti-6Al-4V biomedical prototypes compared to wrought Ti-6Al-4V, Mater. Charact. 60 (2) (2009) 96-105.

[4] X. Gong, T. Anderson, K. Chou, Review on powder-based electron beam additive manufacturing technology, Manuf. Rev. (1) (2014) 1-12.

[5] A.A. Antonysamy, J. Meyer, P.B. Prangnell, Effect of build geometry on the $\beta$ grain structure and texture in additive manufacture of Ti6Al4V by selective electron beam melting, Mater. Charact. 84 (0) (2013) 153-168.

[6] S.S. Al-Bermani, et al., The origin of microstructural diversity, texture, and mechanical properties in electron beam melted Ti-6Al-4V, Metall. Mater. Trans. A 41 (13) (2010) 3422-3434.

[7] A. Safdar, et al., Evaluation of microstructural development in electron beam melted Ti-6Al-4V, Mater. Charact. 65 (0) (2012) 8-15.

[8] H.K. Rafi, et al., Microstructures and mechanical properties of Ti6Al4V parts fabricated by selective laser melting and electron beam melting, J. Mater. Eng. Perform. 22 (12) (2013) 3872-3883.

[9] N. Hrabe, T. Quinn, Effects of processing on microstructure and mechanical properties of a titanium alloy (Ti-6Al-4V) fabricated using electron beam melting (EBM), part 1: distance from build plate and part size, Mater. Sci. Eng.: A 573 (0) (2013) 264-270.

[10] N. Hrabe, T. Quinn, Effects of processing on microstructure and mechanical properties of a titanium alloy (Ti-6Al-4V) fabricated using electron beam melting (EBM), Part 2: energy input, Orientation, Location, Mater. Sci. Eng.: A 573 (2013) 271-277.

[11] L.E. Murr, et al., Microstructure and mechanical behavior of Ti-6Al-4V produced by rapid-layer manufacturing, for biomedical applications, J. Mech. Behav. Biomed. Mater. 2 (1) (2009) 20-32.

[12] M. Koike, et al., Evaluation of titanium alloy fabricated using electron beam melting system for dental applications, J. Mater. Process. Technol. 211 (8) (2011) 1400-1408

[13] P. Edwards, A. O'Conner, M. Ramulu, Electron beam additive manufacturing of titanium components: properties and performance, J. Manuf. Sci. Eng. 135 (2013) 7.

[14] S.L. Lu, et al., Microstructure and mechanical properties of long Ti-6Al-4V rods additively manufactured by selective electron beam melting out of a deep powder bed and the effect of subsequent hot isostatic pressing, Metall. Mater. Trans. A 46 (2015) 3824-3834.

[15] X. Tan, et al., Graded microstructure and mechanical properties of additive manufactured Ti-6Al-4V via electron beam melting, Acta Mater. 97 (2015) $1-16$.

[16] C. Qiu, N.J.E. Adkins, M.M. Attallah, Microstructure and tensile properties of selectively laser-melted and of HIPed laser-melted Ti-6Al-4V, Mater. Sci. Eng.: A 578 (0) (2013) 230-239.

[17] S. Leuders, et al., On the mechanical behaviour of titanium alloy TiAl6V4 manufactured by selective laser melting: Fatigue resistance and crack growth performance, Int. J. Fatigue 48 (0) (2013) 300-307.

[18] B. Vrancken, et al., Heat treatment of Ti6Al4V produced by Selective Lase Melting: microstructure and mechanical properties, J. Alloy. Compd. 541 (0) (2012) 177-185.

[19] T. Vilaro, C. Colin, J.D. Bartout, As-fabricated and heat-treated microstructures of the Ti-6Al-4V alloy processed by selective laser melting, Metall. Mater Trans. A 42 (10) (2011) 3190-3199.

[20] M. Svensson, Arcam. EBM-manufactured Ti6Al4V ELI with $50 \mu \mathrm{m}$ layer, EBM control 3.2 SP1 and scan length dependency, 2012.

[21] L. Germain, et al., An advanced approach to reconstructing parent orientation maps in the case of approximate orientation relations: application to steels, Acta Mater. 60 (2012) 4551-4562.

[22] S. Reginster, et al., Processing of Ti alloys by additive manufacturing: a comparison of the microstructures obtained by laser cladding, selective laser melting and electron beam melting, Mater. Sci. Forum 765 (2013) 413-417.

[23] L. Thijs, et al., A study of the microstructural evolution during selective laser melting of Ti-6Al-4V, Acta Mater. 58 (9) (2010) 3303-3312.

[24] M. Simonelli, T. Yau Yau, C. Tuck, On the Texture Formation of Selective Laser Melted Ti-6Al-4V, Metall. Mater. Trans. A 45 (2014) 2863-2872.

[25] S.M. Gaytan, et al., Advanced metal powder based manufacturing of complex components by electron beam melting, Mater. Technol. 24 (3) (2009) 180-190.

[26] S. Tammas-Williams, et al., XCT analysis of the influence of melt strategies on defect population in Ti-6Al-4V components manufactured by Selective Electron Beam Melting, Mater. Charact. 102 (2015) 47-61.

[27] H. Conrad, Effect of interstitial solutes on the strength and ductility of titanium, Prog. Mater. Sci. 26 (1981) 123-403.

[28] M. Suard, et al., Towards stiffness prediction of cellular structures made by electron beam melting (EBM), Powder Metall. 57 (3) (2014) 190-195.

[29] C. Leyens, M. Peters, Titanium and Titanium Alloys: Fundamentals and Applications, Wiley-VCH, United States, 2003.

[30] C. de Formanoir et al.,Titanium alloy (Ti-6Al-4V) processed by electron beam melting: microstructure and mechanical behavior of the as-built and heattreated material, in: Proceedings of The 13th World Conference on Titanium 2015, San Diego, CA, USA, 2015.

[31] G. Lütjering, J.C. Williams, Titanium - Second Edition, Springer, Germany, 2007.

[32] N. Stanford, P.S. Bate, Crystallographic variant selection in Ti-6Al-4V, Acta Mater. 52 (17) (2004) 5215-5224.

[33] N. Miyano, et al., Reasons for formation of triangular $\alpha$ precipitates in Ti-15V3Cr-3Sn-3Al $\beta$ Titanium Alloy, Mater. Trans. 47 (2) (2006) 341-347. 